\title{
Factors influencing the academic success of Latinx students matriculating at 2-year and transferring to 4-year US institutions-implications for STEM majors: a systematic review of the literature
}

\author{
Erica R. Winterer ${ }^{1}$, Jeffrey E. Froyd ${ }^{2}$, Maura Borrego ${ }^{3}$, Julie P. Martin ${ }^{2}$ and Margaret Foster ${ }^{4^{*}}$
}

\begin{abstract}
This systematic review identifies factors that prior studies have identified as supporting the academic success of Latinx transfer students, who matriculate at 2-year institutions with respect to earning a 4-year baccalaureate degree in a STEM field. Since the students matriculate at a 2-year institution, they must, at some point in their academic career, transfer to a 4-year institution to earn the baccalaureate degree. Search and screening procedures identified 59 qualifying studies describing factors supporting persistence, transfer, or graduation of Latinx students matriculating at 2-year institutions. To synthesize findings, we coded the 31 quantitative, 22 qualitative, and six mixed methods studies according to unified themes. Nearly half the quantitative studies explored student characteristics alone, while some qualitative studies explicitly sought to identify assets Latinx students bring to higher education. None of the quantitative students utilized assets-based frameworks such as Yosso (Race Ethn Educ 8:69-91, 2005) to guide their analysis. All types of studies contributed to the conclusion that quality interactions with peers and staff support success of Latinx STEM transfer students. Specific details and strategies for institutions and their staff to support these interactions are described.
\end{abstract}

Keywords: Community colleges, Latinx, Race/ethnicity, Systematic review, Transfer students

\section{Introduction}

Projected science, technology, engineering, and mathematics (STEM) workforce shortages are a concern in many countries (European Centre for the Development of Vocational Training, 2008; OECD, 2015) and global backlash against immigration is causing focus to shift toward developing STEM talent among citizens (e.g., National Academies, 2016). In the USA, one focus of efforts to develop STEM talent is students who trace their origin to Spanish-speaking countries including, but not limited

\footnotetext{
* Correspondence: margaretfoster@tamu.edu

${ }^{4}$ Medical Sciences Library, University Libraries, Texas A\&M University, MS \#4462, College Station, TX 77843, USA

Full list of author information is available at the end of the article
}

to, Mexico, Cuba, Puerto Rico, and Central and South American countries. This group, which we refer to as Latinx students, is underrepresented in the US STEM workforce but is rapidly growing in both the general population and in education. While the dynamics of diversity and inclusion are specific to each national or regional setting, efforts to develop STEM talent among STEM students are part of a larger worldwide movement for education to be more inclusive of cultural, linguistic, and intellectual diversity (e.g., Florian, 2012; Ferguson, 2008). This systematic review explores factors that influence Latinx students' STEM bachelor's degree attainment, through a particularly promising pathway where 
students matriculate at 2-year community colleges and transfer to 4-year institutions of higher education.

According to the US Census, the Latinx population in the USA is substantial and growing. By 2016, at $17.9 \%$ of the total population, Latinx persons became the largest racial or ethnic minority in the USA (Bauman, 2017). Similarly, in 2016, Latinx students made up almost a quarter of all people enrolled in K-16 institutions (Bauman, 2017), and Latinx students were the largest minority group enrolled in the nation's 4-year institutions in 2012 (Fry \& Lopez, 2012).

Evidence from the literature suggests that 2-year to 4year transfer pathways are important to increasing the number of US Latinx students graduating with STEM baccalaureate degrees. Latinx STEM students enroll in public, 2-year colleges in higher proportions than any other group (National Science Foundation, 2015) and Latinx students account for $25.2 \%$ of traditionally aged students enrolled in 2-year colleges (Fry \& Lopez, 2012). These students are more likely than other groups of students to enroll in programs that lead to transfer compared to technical or vocational programs (National Academies, 2016). Additionally, 2- to 4-year transfer pathways are particularly effective in increasing participation of Latinx students in STEM (Gándara et al., 2012). A study of thirty 4-year and fifteen 2 -year US institutions confirmed higher proportions of Latinx students in engineering and pre-engineering programs in 2year institutions than in 4-year institutions. It also suggested proportions of Latinx students among transfer student populations were higher than in student populations at 4-year institutions (Knight, Bergom, Burt, \& Lattuca, 2014). In the MIDFIELD multi-institutional data set, $40 \%$ of all Latinx students who earned engineering bachelor's degrees were transfer students, compared to $30 \%$ of white students (Camacho \& Lord, 2013). Better understanding of these pathways for Latinx students could lead to increased student attainment of baccalaureate degrees for this underrepresented group. As described below, we argue that a systematic review is needed to analyze prior work, as well as to focus on the success of Latinx students matriculating at 2-year institutions and transferring to 4-year institutions to earn their baccalaureate.

Prior reviews focused on Latinx students in higher education informed this review. One emphasized the need for an empirical body of evidence to inform variable selection in longitudinal national data sets (Nora \& Crisp, 2009). Others also considered only one success outcome (e.g., retention or graduation) which limited their scope (Oseguera et al., 2009; Padilla, 2007). Therefore, we have focused this review on factors influencing success of Latinx students and considered multiple outcomes that indicate their success. The most comprehensive review we identified used inclusion criteria that encompassed multiple academic success outcomes, and the authors synthesized research from several disciplines to explore the success of Latinx undergraduates (Crisp et al., 2015). Given the importance of the 2- to 4-year pathway, we have focused our study on Latinx students matriculating at 2-year institutions and included studies that examined students transferring to 4-year institutions.

Three concerns emerged from studying existing literature that guided our development of the research questions and framing of the discussion for this study. First, we found prior reviews, as well as studies identified in these reviews, tended to highlight factors hindering student success that were characteristics of individual students (e.g., students of lower socioeconomic status succeed at lower rates in higher education). This emphasis on characteristics of individual students depicts, often unintentionally, Latinx students as the primary agents of their academic failure or success and ignores broad societal and educational contexts. Latinx students are often placed into less rigorous educational tracks because of implicit biases (Meier \& Stewart, 1991). Overreliance on the dominant culture in the construction of classroom environments and curriculum development (Ladson-Billings, 1995) and stereotype threat (Walton \& Spencer, 2009) impede the academic success of precollege Latinx students (Crisp et al., 2015). When these contextual factors are ignored and individual student factors that negatively influence success are emphasized in the quantitative analysis of large data sets, student traits can be perceived as deficits. Then, patterns of structural racism and other forms of oppression are ignored and suppressed (Camacho \& Lord, 2013). Identifying individual challenges, absent institutional and cultural context, tends to promote a fix-the-students perspective that perpetuates inequities (Bensimon, 2005; Harper, 2010) or ignores possibilities for systemic institutional change. Instead, addressing historical inequities sustained by societal structures and educational systems requires institutions of higher education to transform to support increasingly diverse student populations (Bensimon, 2005; Harper, 2010). In response to what we perceived as an emphasis in the existing literature on characteristics of individual students, we focused our research questions, findings, and discussion on factors that institutions of higher education and their staff could influence as a precursor to transforming educational systems.

The second concern is that in reported findings, factors identified as hindering student success are often framed in terms of what students lack or deficits that need to be attended to, as mentioned in the previous paragraph. In contrast, Yosso (2005) called for 
approaches that focus on students' cultural capital, or assets, to promote student success. An assets-based perspective, as used in this manuscript, focuses on attributes of students, their resources, and their contexts, on which initiatives to promote their success can build, as opposed to deficits that must be "fixed." As an example of aspirational capital, Latinx students often have dreams "developed within societal and familial contexts, often through linguistic storytelling and advice (consejos) that offer specific navigational goals to challenge (resist) oppressive conditions" (Yosso, 2005, p. 77). Initiatives could build on dreams and specific student motivations instead of emphasizing efforts to "fix" students' lack of preparation. Such assets-based perspectives offer compelling alternatives to deficit perspectives (Harper, 2010), which often recharacterize educational inequities as stereotypical traits based on race, ethnicity, a culture of poverty, and related factors (Bensimon, 2005). Interventions based on a deficit perspective typically identify a group of students with a specific deficit (e.g., low mathematics ability) and develop an intervention for this group. As a result, these interventions, based on our systematic review of interventions intended to support success of Latinx students (Martin et al., 2017), tend to be supplemental interventions designed to fix students. On the other hand, assets-based interventions build on dreams, specific student motivations, and students' cultural capital. Since all students have dreams, motivations to succeed in higher education, and cultural capital, assets-based interventions tend to address all students, thus requiring institutional action (e.g., Brown \& Kurzweil, 2017; Holloway, Reed, Imbrie, \& Reid, 2014) and necessitating accountability among administrators, instructors and staff to produce equitable educational outcomes for all students. To address our second concern, we attempt to deemphasize deficit-based perspectives in reporting our findings by focusing on student experiences and factors institutions of higher education can influence.

The third concern is an overreliance on the Tinto (1993) model of student attrition, as well as similar models that have built on Tinto's work (Crisp et al., 2015). A review of Tinto's work and associated models is beyond the scope of this paper. Oversimplified, Tinto's model and associated models focus on characteristics of individual students (e.g., goal commitments) and what individual students can do to improve success (e.g., assimilate to existing campus communities). Critiques of Tinto's theory and other models based on his work focus on several points. First, these models emphasize individual characteristics and decisions influencing student success and deemphasize contextual factors that influence the academic success of students. This point has the same consequence of our first concern above, namely the choice of characteristics of individual students as factors to be studied, but the reasoning underlying the choice of factors to be studied is different. Second, although Tinto's model has changed over the course of the 35 years from which it was originally introduced (Demetriou \& Schmitz-Sciborski, 2011), critiques of the theory point out how Tinto defines students traditionally (e.g., full-time, 18-22-year-old students living on campus) and describes cultural assimilation to the dominant Eurocentric culture as the norm rather than promoting the evolution of campuses to value the distinct and diverse assets Latinx students bring from their cultural values and experiences (Crisp et al., 2015; Lee et al., 2018; Oseguera et al., 2009). Lastly, critics point out that the model separates necessarily entangled social and academic integration constructs (Lee et al., 2018).

In addition to these critiques, variations in how multiple studies have operationalized the theoretical constructs (i.e., social integration and academic integration) are problematic (Crisp et al., 2015; Lee et al., 2018). The operationalization is inconsistent from study to study and often defined one-dimensionally so that studies are unable to fully capture complex phenomena. Crisp et al. (2015) concluded that the absence of a cohesive theoretical framework throughout the literature makes it difficult for results to inform policy and practice. They therefore called for integration of Latinx students' cultural values and experiences into theoretical frameworks focused on the assets within this population. Ultimately, the Tinto model depicts students as the primary agents determining their success and as such does not provide a framework for generating institutional actions (e.g., programs and policies) for improving academic success of Latinx students. To facilitate the development of such a framework, there is a need for literature that shifts the focus from individual students to institutions and their staff.

A systematic review could have multiple benefits in the development of this framework (Petticrew \& Roberts, 2006). First, a rigorously and transparently conducted review gives the reader an opportunity to assess the approach and conclusions. Second, systematic reviews provide a clear overview of a topic, presenting what is known and what is not known. Such clarity informs decisions when designing or funding future research, interventions, and programs. These reviews can clarify which factors evidence suggests have influence, which whose influence it does not support, and which require further study to guide future work. Finally, systematic review methods identify, capture, and synthesize the collective wisdom in primary studies with the populations and outcomes of interest (Borrego et al., 2014). To promote an assets-based perspective we will emphasize factors that institutions and their staff can 
influence to support bachelor's degree attainment among Latinx students who enter higher education at 2-year institutions.

These questions guided this systematic review:

- What factors, including factors that institutions of higher education can influence, factors related to influences of interactions with instructors and/or other staff, and factors over which an institution has little or no direct control (e.g., student characteristics), have prior studies identified as supporting the success of Latinx transfer students?

- What are factors that institutions and their staff can influence? (Note: We included this research question since our study of existing literature suggested an overemphasis on student characteristics and the research question serves to highlight our emphasis on highlight other factors in our systematic review.)

- What, if any, are the special considerations for STEM majors?

\section{Method}

Our systematic review relied on methods detailed by Borrego et al. (2014); Gough et al. (2012); and Petticrew and Roberts (2006) as described below. Systematic reviews are research syntheses that can vary in the types of studies combined, either only qualitative or quantitative studies, or they can integrate results from both types of studies. In the studies identified in this review, the success outcomes varied widely, and consideration of all types of empirical approaches were used to inform the review.

Our emphasis on Latinx students matriculating at 2year institutions contrasts with prior reviews that focused on student success at 4-year institutions. Since there are few studies that addressed Latinx STEM transfer students, we included studies of transfer students of all race/ethnicities, Latinx students at 2-year institutions, and students at Hispanic-serving institutions (HSIs). We defined success broadly, but traditionally, as persistence for at least one semester, transfer to a 4-year institution, or graduation from a bachelor's degree program. We did not limit the type of study to those with quantitative evidence of student success. Many of the quantitative studies we reviewed follow the US Census terminology of Hispanic. For consistency, we use a single term (Latinx), while acknowledging that Latinx students are a heterogeneous group and that individuals may prefer other terms based on their geographic and political backgrounds (Camacho \& Lord, 2013).

\section{Search procedures}

Foster searched several databases with agreed-upon search terms to retrieve relevant studies. These databases included ERIC (Ebsco), Academic Search Complete (Ebsco), and Compendex (Engineering Village). The search included the concepts (STEM or engineering or Latinx) and (transfer) and (two-year college) as well as synonyms and thesaurus terms for each concept. Foster constructed the ERIC search syntax before translating it for following database searches. The search spanned January 1, 1980, to June 24, 2016, the date it took place. All records were exported to RefWorks (Refworks, n.d.) and duplicates were removed. Scopus was used to locate references to highly related studies and included studies.

\section{Inclusion criteria}

For inclusion in this review, studies must have included the following characteristics:

- Student population: Latinx students enrolled in 2year institutions, students in 2-year Hispanic-serving institutions, or 2- to 4-year transfer students; US institutions only

- Success outcome: Transfer, retention, graduation, satisfaction, financial aid/knowledge, and success in one course or one semester

- Format: Report, journal article, conference paper, or dissertation in English published since 1980, when US Census procedures changed how they reported Latinx respondents (Cohn, 2010)

- Evidence: Quantitative and/or qualitative, empirical evidence connecting a factor to its influence on one or more of the identified student outcomes

To determine the selection of studies from the search results, Foster randomly assigned two authors to read each study and answer a series of questions using Qualtrics web-based survey software. The questions addressed both eligibility criteria and characteristics of the study. We resolved disagreements through discussion and then divided the studies based on their methods.

\section{Coding and quality assessment}

Two researchers independently coded each of the quantitative studies using the online Qualtrics form. After coding a subset of quantitative studies, the two authors met to review how they coded each study. If they disagreed on coding an aspect of a study, they reviewed the study and reached consensus on how to code the aspect of the study. They repeated this process until they reached consensus on coding each aspect of the study. Since there were many aspects of each study, they did not track disagreements on an aspect-by-aspect basis, so the frequency of disagreements was not recorded. The following characteristics were coded: 
- Type of resource: Report, journal article, conference paper, or dissertation

- Population: Latinx or students at HSI, Black or other minority, women, STEM majors, transfer students, 2-year institution, and single or multi-institution

- Results: Factors considered and success outcomes

After initial coding, Froyd and Winterer collected more detailed information by organizing all significant factors from each quantitative study and the specific data sources used in the study into a comprehensive spreadsheet. All authors collaborated to produce a quality score rubric (Table 1) for quantitative studies. The rubric produced an overall quality score between 0 and 7 points by evaluating aspects of the study design including number of institutions, sample size, longitudinal or cohort data, and sophistication of statistical analyses.

The selection of the criteria was based, in part, on recommendations for educational research (Coalition for Evidence-Based Policy, 2007; Towne \& Shavelson, 2002; Turner et al., 2013). We considered these recommendations and the context of our sample to develop a scoring system that, in general, awarded higher scores to studies that were more generalizable, as generalizability is an expectation of quantitative research. For example, we awarded points to studies that included multiple institutions and larger sample sizes as these factors would likely lead to more generalizability. The specific sample size in criterion 2 was chosen because a review of the sample sizes in the identified studies showed the number chosen was a demarcation between smaller and larger sample sizes. Studying the same participants over time (e.g., a longitudinal study) would also more likely yield generalizable results compared to studies that only consider participants at a single point in time. Further, studies that considered multiple factors simultaneously (e.g., regression, correlation) would likely yield more generalizable results than studies that only considered one factor at a time (ANOVA or $t$ test). Although criterion 4 does not list all possible quantitative analysis approaches, the authors thought it provided sufficient distinction between the approaches found in the identified quantitative studies. Finally, as it is an accepted practice, we believed studies that explicitly acknowledged limitations would be more likely to yield generalizable results compared to studies that did not. Based on these considerations, the authors generated the quality appraisal scheme in Table 1.

Martin coded the qualifying qualitative studies for the following characteristics: study population, one or multiple institutions, research purpose, and major findings. Martin evaluated these studies to produce a quality score of "low," "medium," or "high" by assessing their adherence to Guba and Lincoln's (1989) authenticity criteria: fairness, ontological authenticity, educative authenticity, catalytic authenticity, and tactical authenticity.

The screening and selection process identified six mixed methods studies. Borrego coded these studies for study population, one or multiple institutions, research purpose, and major results. The quality assessment of these studies was based on criteria for mixed methods studies (Creswell \& Plano Clark, 2007), which included

Table 1 Quality appraisal for quantitative study

\begin{tabular}{|c|c|c|}
\hline Number & Question/possible answers & Points \\
\hline Criterion 1 & What was the institutional setting? & \\
\hline $1 \mathrm{a}$ & Multiple institutions & +1 \\
\hline $1 b$ & One institution & +0 \\
\hline Criterion 2 & What was the sample size? & \\
\hline $2 a$ & Sample size equal to or more than 500 participants & +1 \\
\hline $2 b$ & Sample size smaller than 500 participants & +0 \\
\hline Criterion 3 & Was the study a longitudinal design (i.e., data at multiple times for at least one cohort of students)? & \\
\hline $3 a$ & Yes, it was a longitudinal study. & +1 \\
\hline $3 b$ & No, it was not a longitudinal study. & +0 \\
\hline Criterion 4 & What method(s) were used to test relationship(s) between independent and dependent variables? & \\
\hline $4 a$ & Regression & +3 \\
\hline $4 b$ & Correlation & +2 \\
\hline $4 C$ & ANOVA or $t$ test & +1 \\
\hline $4 d$ & Descriptive analysis & +0 \\
\hline Criterion 5 & Did author describe the limitations of the study? & \\
\hline $5 a$ & Yes & +1 \\
\hline $5 b$ & No & +0 \\
\hline
\end{tabular}


(a) distinctive quantitative and qualitative approaches; (b) mixed methods, designs, visualizations, and citations; and (c) mixing quantitative and qualitative data. Scores were generated by giving two points for each of the three items, for a maximum score of six points.

To synthesize results across studies and make meaning of the factors, we created categories. We started with categories based on findings we synthesized from the qualitative studies. Then, we identified common statistically significant factors from the quantitative studies. We aligned the quantitative and qualitative categories where possible and created new categories as needed. We repeated this process for the mixed methods studies. Then, we grouped the categories of factors into Tables 3, 4, and 5 using the rationale described below.

\section{Limitations}

Several limitations of this approach should be noted. Our list of qualifying studies may not be complete. Omitted studies may be unpublished, not indexed in the databases we used, or otherwise not captured by our search parameters. Additionally, we excluded many studies about the success of Latinx students in 4-year institutions if we could not readily identify that they included transfer students. We may have omitted some studies that included transfer students, albeit not prominently enough. Our procedure of separating intervention studies for a different analysis and publication may have deemphasized certain factors, such as teaching, which can be framed either as a specific intervention or more generally as a factor. Additionally, the broad scope of this review does not address aspects of intersectionality that may influence the success of students. For example, the experiences of Black or Latina women in engineering may diverge from these findings. We also do not include student populations that begin their postsecondary education at 4-year institutions.

\section{Results}

Sample

Figure 1, modeled after Knobloch et al. (2011), illustrates the number of studies flowing through the initial search, selection, and coding process. After an initial search yielded 2732 results, we included 170 studies for

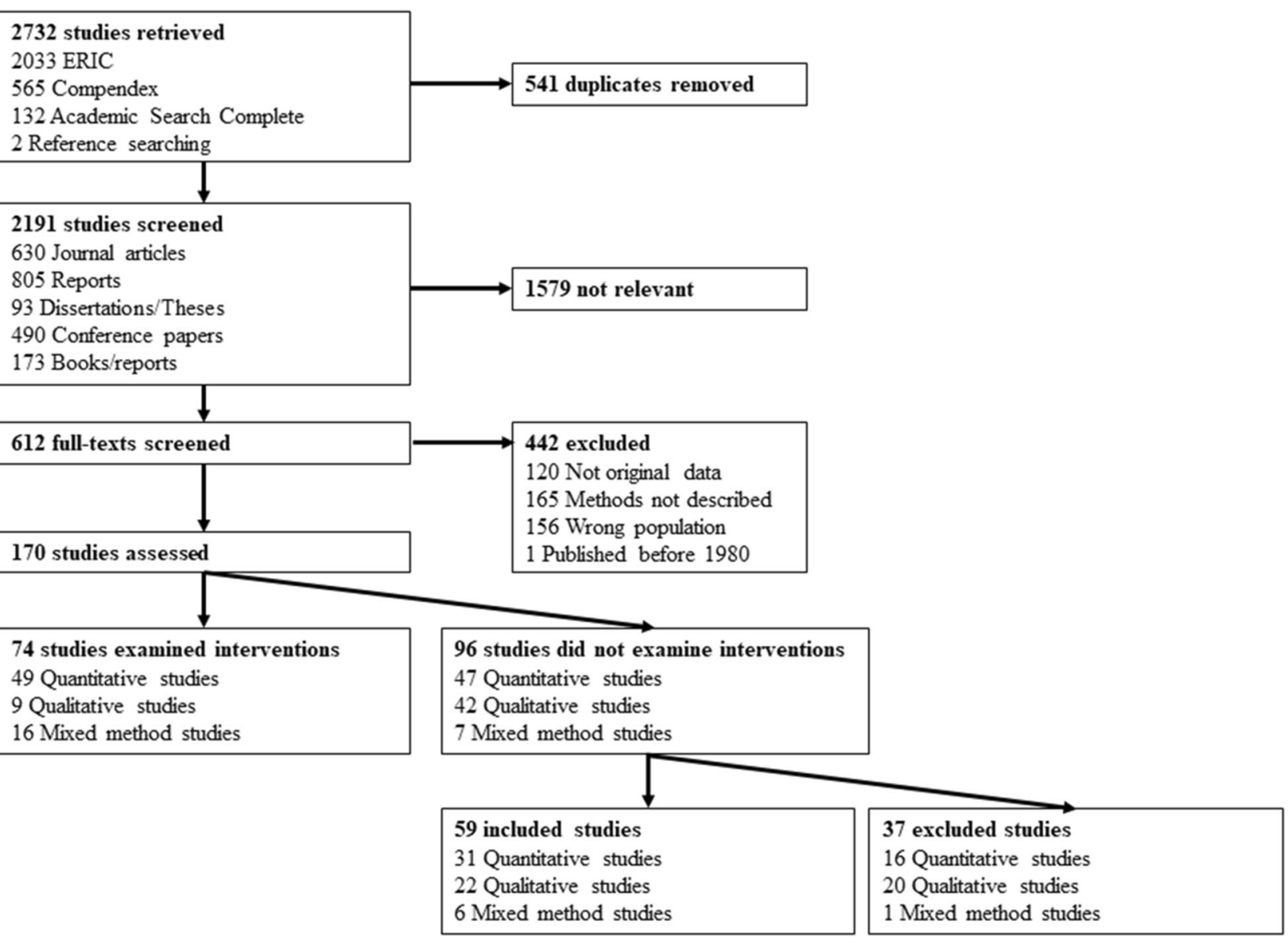

Fig. 1 Article screening process. This figure illustrates the flow and number of studies through the search, selection, and coding processes 
analysis. Of these, 74 studies examined interventions related to specified success outcomes and were included in a previous paper (Martin et al., 2017). From the 96 remaining studies that did not examine interventions, we identified 59 studies that met all inclusion criteria and addressed factors related to student success outcomes.

We excluded studies as irrelevant that the original keyword search had identified for varying reasons. The search string necessarily included some general terms to identify studies of transfer students. As a result, the search returned many papers that used these terms in other ways (e.g., heat/mass transfer, transition state, knowledge transfer). We also excluded many state and institutional reports of student enrollment disaggregated by ethnicity because they did not address any outcomes of interest. Other common reasons for excluding studies included examination of the wrong population, no documented methods, and lack of evidence supporting assertions in the study.

Table 2 summarizes the study populations across quantitative, qualitative, and mixed methods studies. In the results sections that follow, quantitative studies labeled "high" earned a score of 6 or 7, "medium" earned 4 or 5, and "low" earned 1-3 points.

One notable and somewhat surprising result reported in Table 2 is that only two of the studies were specifically about Latinx STEM transfer students. However, an effective synthesis of all 59 studies can provide a foundation for current action and future research for this specific population. Relevant insight can be gleaned from considering studies that investigate Latinx student success, more generally, as well as ones that investigate STEM transfer success specifically. First, a key to studying success of Latinx STEM transfer success is that students must be successful in 2-year institutions before transfer. Many of the studies identified in Table 2 focused on experiences of Latinx students in 2-year institutions and contribute useful insights. Further, in many studies of Latinx students in 2-year institutions, students are not specifically identified as STEM majors or not. If all participants in a study were all in non-STEM majors, we excluded the study. However, we did not exclude studies in which we were unable to discern if the study participants were STEM or non-STEM majors. Therefore, we included studies shown in the second, third, and sixth rows in Table 2. Further, studies of transfer students that included Latinx students, but did not focus on solely on Latinx students, offered valuable findings, as well. Therefore, we included studies shown in the fourth and fifth rows in Table 2. Although we identified only two studies of factors influencing success of Latinx STEM transfer students specifically, findings from all 59 studies shown in Table 2 offer valuable insights for synthesis.

As discussed previously, student experiences (e.g., peer relationships and quality of advising) that are likely to be independent of academic major often influence student success outcomes. Therefore, our systematic review includes factors influencing academic success common to the majority of Latinx students regardless of their major. In addition, we included studies that considered factors influencing students' matriculation at 2-year institutions (e.g., success in writing, mathematics, and science courses as well as developmental courses in these subject areas) that are important to success of all students in the 2 -year institutions. The findings from these studies are important to our consideration of factors influencing success of students that matriculate at 2-year institutions because students must be successful at 2-year institutions, successfully transfer, and successfully complete curricula at 4-year institutions to earn a baccalaureate STEM degree.

Therefore, our review synthesizes findings from the 59 studies in Table 2 to facilitate translation, synthesis, abstraction, and application of these results for Latinx STEM transfer students. Our discussion calls for structural changes to be made in higher education institutions to benefit all Latinx students matriculating at 2year institutions, including those majoring in STEM disciplines. Some of these changes can be implemented at 2-year institutions, some can be implemented by

Table 2 Summary of all study populations

\begin{tabular}{|c|c|c|c|c|}
\hline \multirow[t]{2}{*}{ Population } & \multicolumn{3}{|l|}{ Method } & \multirow[t]{2}{*}{ Total } \\
\hline & Quantitative & Qualitative & Mixed methods & \\
\hline Latinx STEM transfer & 0 & 2 & 0 & 2 \\
\hline Latinx transfer & 7 & 1 & 0 & 8 \\
\hline Latinx success in 2-year institution & 10 & 10 & 4 & 24 \\
\hline STEM transfer & 7 & 8 & 2 & 17 \\
\hline STEM success in 2-year institution & 5 & 1 & 0 & 6 \\
\hline Transfer & 2 & 0 & 0 & 2 \\
\hline Total & 31 & 22 & 6 & \\
\hline
\end{tabular}


partnerships between 2-year and 4-year institutions, and some can be implemented by 4-year institutions. All of the changes will, we argue, contribute to the success of Latinx students matriculating at 2-year institutions who will need to transfer and be successful at 4-year institutions to earn baccalaureate degrees in STEM majors.

Tables 3, 4, and 5 present synthesized results across all 59 studies, separated by the entity that influences student success-institutions (Table 3), instructors and other staff (Table 4), and students and their families (Table 5) - and the factors identified using qualitative or quantitative data. Results from mixed methods studies were separated into qualitative and quantitative results. A blank cell in a table shows that we did not identify any studies using data of that type that supported the influence of a particular factor. As noted, an asterisk indicates a mixed methods study and a dagger indicates studies focused on STEM students.

\section{Institutions}

Table 3 focuses on factors that institutions of higher education can influence to support the success of Latinx students who matriculate at 2-year institutions. It shows eight factors in order of decreasing number of studies: peer interactions, cultural climate, advising, coursework articulation, academic integration, support services, assets-based factors, and outreach. Fifteen of the 31 quantitative studies, 20 of the 22 qualitative studies, and one of the six mixed methods studies presented findings in one or more of the eight factors related to institutions. All but two of the 20 qualitative studies were published after 2010, suggesting that qualitative inquiries focusing on factors that institutions influence to support the success of Latinx students is a recent trend.

\section{Peer interactions}

The success factor that the largest number of studies $(8$ qualitative and 6 quantitative) supported was peer interactions, which quantitative studies sometimes included as part of the "social integration" variable (Crisp et al., 2015). Peer interactions included participation in school organizations, social integration, and supportive peer relationships. Quality of the studies supporting peer interactions ranged across our quality scale, with approximately half of the studies scoring high. Fourteen studies overall, including six high-quality studies, provide strong evidence that improving peer interactions at an institution would likely improve success of Latinx students.

Quantitative studies can identify the significance of factors but not processes through which these relationships influence student success. The qualitative studies help to develop a deeper understanding of the nature of the processes. Participants in qualitative studies acknowledged peer relationships as a vital component to both their academic success and emotional well-being (Barbosa and Seton Hall University, 2011; Dorame, 2012; Patterson, 2011; Wade, 2012). They commonly expressed gratitude for deep friendships that developed from time spent in study groups or working with other students in a class. However, students found that they needed to be strategic in choosing peers with whom to collaborate. Some cited the importance of choosing friends who are supportive of them pursuing an education (Barbosa and Seton Hall University, 2011; Prado, 2012), while others were drawn to students with similar backgrounds and experiences (Allen \& Zhang, 2016; Wade, 2012). Students reported peers can influence important decisions such as choice of major, degree aspirations, and persistence in their course work (Dorame, 2012; Martin et al., 2013). Peer relationships can validate students' STEM identity and provide them with a sense of community to support their academic performance and motivation to persist (Barbosa and Seton Hall University, 2011; Martin et al., 2013). Overall, these studies suggest that forming resilient peer relationships could positively impact students' trajectories as these relationships play such a significant role in their success.

Studies also identified barriers that could make it difficult for students to develop relationships and have productive peer interactions. For example, if there are few students with a similar background in a course or at the institution, it may be difficult for underrepresented minority students to form a project group (Wade, 2012). Transfer students also reported having a difficult time finding and/or maintain a study group because established groups were difficult to enter and connections dissolved due to inconsistent enrollment (Prado, 2012; Patterson, 2011; Wade, 2012).

\section{Cultural climate}

Cultural climate included factors such as diverse student population (i.e., racial representation of the student body, in three high-quality quantitative studies), accessible instructors, affordable tuition, engagement with institutional agents, students' cultural affinity (perception they belong at institution), acculturative stress (one mixed methods study), and the number of Latinx instructors at 2-year institutions. Among the quantitative studies supporting cultural climate, four of the seven were high quality and the rest were medium, indicating the support from quantitative studies was strong. All five qualitative studies were low to medium quality. In summary, 13 studies support the strength of the influence of cultural climate, but the quality of the studies varied.

In multiple qualitative studies, students reported an expectation at their institution that they should know all rules and policies for navigating the system (Barbosa and 
Table 3 Findings with institutions as the locus of control

\begin{tabular}{|c|c|c|}
\hline Finding & Qualitative findings & Quantitative results \\
\hline $\begin{array}{l}\text { Peer } \\
\text { interactions }\end{array}$ & $\begin{array}{l}\text { Supportive peer relationships positively impact student outcomes. } \\
\text { Barbosa and Seton Hall University (2011), Cejda and Hoover (2011), } \\
\text { Dorame (2012), Martin (2013) })^{\dagger} \text {, Ozuna Allen }(2016)^{\dagger} \text {, Patterson } \\
(2011) \text {, Prado (2012), Wade }(2012)^{\dagger}\end{array}$ & $\begin{array}{l}\text { Participation in school organizations (e.g., clubs, sports) positively } \\
\text { impacts student outcomes. } \\
\text { LaSota and Zumeta (2016) } \\
\text { Social interaction positively impacts student outcomes. } \\
\text { Massi et al. }(2012)^{\dagger} \text {, Marra et al. (2015) }{ }^{\dagger} \text {, Museus et al. (2012), Nora } \\
\text { (1987) }\end{array}$ \\
\hline
\end{tabular}

Cultural Various factors (e.g., affordable tuition, flexible schedule, diverse climate student population, accessible instructors) in community college environments help students feel comfortable and secure, which should support positive outcomes.

Alexander et al. (2007), Barbosa and Seton Hall University (2011), Coley $(2015)^{\dagger}$, Jackson $(2013 b)^{\dagger}$, Zhang $(2015)^{\dagger}$

Empowerment of students can be supported by engagement with institutional agents, student organizations, and Chicano studies classes.

Wilson $(2012)^{*}$
Advising Students perceive advising/counseling support as important to their outcomes.

Arteaga (2015), Dorame (2012), Jackson (2013b) ${ }^{\dagger}$, Patterson $(2011)^{\dagger}$ Sayasenh (2012), Wade (2012) ${ }^{\dagger}$

Variability in how students experience the quality of advising services can negatively impact students' aspirations and/or delay transfer or matriculation.

Arteaga (2015), Ramirez (2011), Packard et al. (2012) ${ }^{\dagger}$

Academic Participation in tutoring/study groups/learning communities integration positively impacts student outcomes. Patterson $(2011)^{\dagger}$, Sayasenh (2012), Wade $(2012)^{\dagger}$

Support Delays in students' awareness of campus resources and difficulty services accessing these services (e.g., counseling, computer labs, tutoring labs) negatively impact student outcomes.

Lee (2014), Prado (2012), Martin (2013) ${ }^{\dagger}$, Packard et al. (2012) ${ }^{\dagger}$

Coursework Alignment of program curricula and consistent communication articulation between community colleges and universities supports student transfer.

Jackson $(2013 a)^{\dagger}$, Jackson $(2013 b)^{\dagger}$, Packard et al. $(2012)^{\dagger}$, Patterson $(2011)^{\dagger}$, Turner (1990), Packard et al. (2012)

Assets- Yosso's (2005) community and cultural wealth framework

based facilitates assets-based investigations of Latino transfer and

framework community college students.

Lee (2014), Matos (2015), Ramirez (2011)

Outreach Efforts to increase knowledge around higher education are more effective when they occur early in students' K-12 education (elementary/middle school) and include students' families and their communities.

Dorame (2012), Matos (2015)
Racial representation (\% of student body that shares the student's racial background) positively impacts student outcomes.

Budd and Stowers (2015), Gross et al. (2014), Museus et al. (2012)

Campus climate, support services, and students' cultural affinity

(perception they belong at institution) positively impacts student outcomes.

Elrod (2002), Nora et al. (1997)

There was a significant, negative correlation between acculturative stress and persistence at a single institution.

Wilson $(2012)^{*}$

Number of Hispanic instructors at community college districts positively impacts transfer rates of Hispanic students.

Klement and Bower (2012)

Students' positive perception of experience positively impacts their outcomes.

McCool (1984)

Quality and frequency of academic advising/registration experiences positively impact student outcomes.

\section{Elrod (2002), LaSota and Zumeta (2016) ${ }^{\dagger}$, Myers $(2013)^{\dagger}$}

Academic involvement, integration, and adjustment positively impacts student outcomes.

Castillo (2011), Griffin (2010), Nora (1987), Museus et al. (2012)

Campus climate, support services, and students' cultural affinity (i.e., perception they belong at institution) positively impacts student outcomes.

Elrod (2002), Nora et al. (1997)

Existence of a statewide transfer guide positively impacts student outcomes. The use of common course numbering across a state positively impacts student outcomes for first--generation students.

LaSota and Zumeta (2016) ${ }^{\dagger}$ 
Table 4 Findings with higher education instructors and other staff as the locus of control

\begin{tabular}{|c|c|c|}
\hline Finding & Qualitative findings & Quantitative results \\
\hline $\begin{array}{l}\text { Instructors/ } \\
\text { staff } \\
\text { interactions }\end{array}$ & 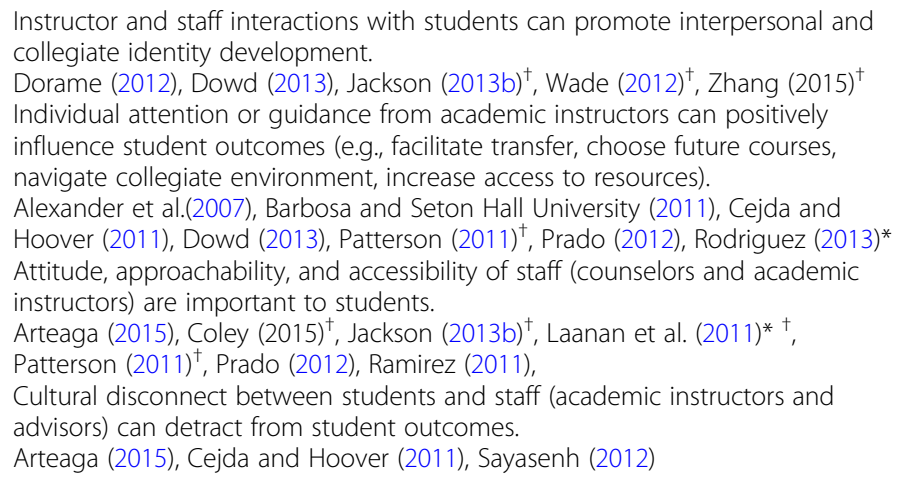 & $\begin{array}{l}\text { Academic involvement, integration, and adjustment } \\
\text { positively impacts student outcomes. } \\
\text { Castillo (2011), Griffin (2010), Museus et al. (2012), } \\
\text { Nora (1987) } \\
\text { Student-instructor interactions positively impact } \\
\text { student outcomes. } \\
\text { Del Rio (2013), Marra et al. (2015) }{ }^{\dagger}, \text { Nora et al. } \\
\text { (1997) } \\
\text { Encouragement from instructors and other staff } \\
\text { inside an institution positively impacts student } \\
\text { outcomes. } \\
\text { Myers }(2013)^{\dagger}, \text { Nora (1987) }\end{array}$ \\
\hline Teaching & $\begin{array}{l}\text { Instructional strategies that promote peer to peer interaction (e.g., group work, } \\
\text { student-centered instruction, student-led instruction) positively impact student } \\
\text { outcomes. } \\
\text { Barbosa and Seton Hall University (2011), Cejda and Hoover (2011), Prado } \\
\text { (2012) } \\
\text { Culturally responsive teaching/relevant curriculum positively influences } \\
\text { engagement and outcomes of students. } \\
\text { Alexander et al. (2007), Barbosa and Seton Hall University (2011) }\end{array}$ & \\
\hline
\end{tabular}

*Mixed methods

${ }^{\dagger}$ STEM population

saw their 2-year college with a large Latinx population as an extension of their community. Jackson (2013a) reported a similar finding for African American STEM students transferring to a historically black institution, which they described as a safe space to develop their STEM identity.

A few studies described aspects of campus or classroom climates that can be difficult for transfer students to navigate. One transfer student who had positive experiences with 2-year college instructors described a "chilly climate" in a 4-year university STEM course. She explained that when she asked questions, her peers ignored her, and the instructor did not intervene or make her feel supported. This led her to participate less. A second student also felt like some of her university professors did not like to answer questions and did not consider teaching a priority (Jackson, 2013b). In Coley and Vallas (2015), a student recounted an experience in class where non-transfer students drew upon previous knowledge to complete a task. As a transfer student, he lacked this knowledge and had trouble with the assignment. It emphasized how much he had missed in comparison to the non-transfer students and his feelings of disconnection from his cohort. Other transfer students in the same study described that if they came in during their third year, all the non-transfer students are already connected. This leads the transfer students to form their own study groups when they have the same course. Transfer students also expressed that starting over with a 0.00 GPA after transfer, in their third year when classes are the most difficult, creates a climate of extreme pressure in the transfer student community.

\section{Advising}

Influence of advising/counseling on success of Latinx students was supported by 11 studies (eight qualitative and three quantitative). Qualitative studies (all high or medium quality) focused on how students perceived and/or experienced advising, which quantitative studies could not provide. Among these, six support a finding that students perceive advising support as important to their outcomes. While advising can support student success, three qualitative studies report that variability in how students experience the quality of advising services can negatively impact their aspirations or delay transfer or matriculation. Quantitative studies (two of the three were high quality) showed that the quality and frequency of advising were positively correlated with perceived success with respect to outcomes. The number of studies and the overall quality of both the qualitative and quantitative studies supporting influences of advising indicates that improving advising experiences for Latinx students would likely yield improvements in student outcomes.

Multiple qualitative studies showed students recognized the importance of academic advisors in navigating higher education (Arteaga, 2015; Jackson, 2013b; Sayasenh, 2012). This was especially true for first-generation students, who may not be able to rely on their families for guidance (Arteaga, 2015). All of the 26 firstgeneration, low-income, Latinx 2-year college students who participated in the Arteaga (2015) study reported relying on counselors for guidance in many areas beyond course selection, including when to register for classes; preferred instructors; developing a plan to reach their educational goals; referrals to campus resources such as 
Table 5 Findings on characteristics of students, their families, and their communities

\begin{tabular}{ll}
\hline Findings & Qualitative findings \\
\hline Race/ethnicity & \\
Gender & \\
Age & Alexander et al.(2007), Prado (2012) \\
Preparation & \\
Start at 2-year &
\end{tabular}

Student's surrounding geography or institution Lower English language competency negatively impacts student outcomes. Alexander et al. (2007), Lee (2014)
English competency

Quantitative results

Filipino and Hawaiian students are less likely to transfer than White and Japanese students.

Libarios (2013)

African American and Hispanic students comprise low proportions of non-transfer engineering students. Hispanic students highly represented in the transfer population.

Knight et al. (2014)

African American and Hispanic students experience negative effects on general

outcomes while Asian student experience positive effects.

Nutting (2011)

Being a female student correlates with positive student outcomes.

Gross et al. (2014), Libarios (2013) ${ }^{\dagger}$, Nutting (2011)

Female students are less likely than males to intend to transfer into a STEM major.

Myers et al. (2015)

Increases in age of student negatively impact student outcomes

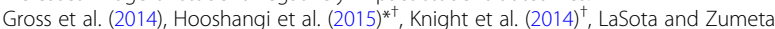

$(2016)^{\dagger}$, Libarios $(2013)^{\dagger}$, Myers $(2013)^{\dagger}$, Nutting (2011), Wood et al. (2012),

Increases in age of student positively impact students' intention to transfer into a

STEM major.

Myers et al. (2015)

Enrolling in community college as first postsecondary institution correlates negatively with students' STEM baccalaureate success.

Wang $(2015)^{+}$

Completion of an Associate Degree or Certificate may correlate positively with

student outcomes if the completion of the degree does not significantly delay student progress.

Mooring and Mooring (2016), Nutting (2011)

Choosing to enroll at the 4-year campus nearest to a student's 2-year campus

correlates negatively with student outcomes.

Nutting (2011)

Non-US resident students have better outcomes than citizens.

Nutting (2011)

Enrollment in developmental coursework correlates negatively with student outcomes.

Crisp and Delgado (2014), Gross et al. (2014), LaSota and Zumeta (2016) ${ }^{\dagger}$

Higher GPAs correlate positively with student outcomes.

Chen and Soldner (2013) ${ }^{\dagger}$, Griffin (2010), Gross et al. (2014), LaSota and Zumeta

$(2016)^{\dagger}$, Laugerman and Shelley $(2013)^{\dagger}$, Laugerman et al. $(2015)^{\dagger}$, Marra et al. (2015) ${ }^{\dagger}$, Mooring and Mooring (2016), Nutting (2011)

Higher high school GPAs correlate positively with student outcomes.

Knight et al. (2014) ${ }^{\dagger}$, Nora (1987), Wood et al. (2012)

Higher SAT scores correlate positively with student outcomes.

Libarios (2013)

The level of education in the area surrounding a college correlates with a lower rate of transfer among Latinx community college students.

Budd and Stowers (2015)

Higher average transfer-out rate of institution correlates positively with student outcomes.

LaSota and Zumeta (2016)

Gross state product correlates positively with student outcomes.

LaSota and Zumeta (2016)

2-year institutions with higher percentages of African American students exhibit

lower transfer rates. Those with higher proportions of students under the age of 25 exhibit higher transfer rates.

Wassmer et al. (2004)

Increases in county population density indicating an "urban" environment correlates positively with transfer rates of 2-year institutions in that country. Wassmer et al. (2004)

Students for whom English is their first language are less likely to transfer Libarios (2013)

Students for whom English is not their first language are more likely to intend to transfer into a STEM major.

Myers et al. (2015)

Enrollment in English developmental coursework correlates negatively with student outcomes.

Crisp and Delgado (2014)

First-generation

Lack of familiarity with higher education (e.g., first-generation students) negatively impacts student outcomes.

Lee (2014), Martin (2013) ${ }^{\dagger}$, Matos (2015), Ramirez (2011), Sanchez $(2012)^{*}$, Sayasenh (2012)

First-generation college student status correlates negatively with student outcomes. LaSota and Zumeta (2016) ${ }^{\dagger}$, Wood et al. (2012)

Increased levels of parents' education positively impact student outcomes. Del Rio (2013), Griffin (2010), Knight et al. (2014) ${ }^{\dagger}$, Myers $(2013)^{\dagger}$, Nora (1987)

Lack of a clear sense regarding relevance of higher education

negatively impacts student outcomes.

Alexander et al. (2007), Coley (2015) ${ }^{\dagger}$, Prado (2012) 
Table 5 Findings on characteristics of students, their families, and their communities (Continued)

\begin{tabular}{|c|c|c|}
\hline Findings & Qualitative findings & Quantitative results \\
\hline Family support & $\begin{array}{l}\text { Family support, one of six types of community cultural wealth capital } \\
\text { (Yosso, 2005), correlates positively with student outcomes. } \\
\text { Barbosa and Seton Hall University (2011), Dorame }(2012) \text {, Jackson } \\
(2013 \mathrm{~b})^{+} \text {, Matos (2015), Sayasenh (2012), Zhang }(2015)^{+}\end{array}$ & $\begin{array}{l}\text { Encouragement from students' families correlates positively with student outcomes. } \\
\text { Nora (1987), Nora et al. (1997) }\end{array}$ \\
\hline Finances & $\begin{array}{l}\text { Limited financial resources negatively impact student outcomes. } \\
\text { Alexander et al. (2007), Anderson et al. }(2011)^{\dagger} \text {, Dorame (2012), Lee } \\
(2014) \text {, Patterson }(2011)^{\dagger} \text {, Sanchez }(2012)^{*} \text {, Sayasenh }(2012) \text {, Packard et } \\
\text { al. }(2012)^{+}\end{array}$ & $\begin{array}{l}\text { Strained personal finances correlates negatively with student outcomes. } \\
\text { Griffin (2010), Kruse }(2015)^{\dagger}, \text { Myers et al. }(2015)^{+} \\
\text {Single parent status, having dependent children or having a spouse correlates } \\
\text { negatively with student outcomes. } \\
\text { Griffin (2010), Wood et al. (2012) } \\
\text { Financial aid correlates positively with student outcomes. } \\
\text { Gross et al. (2014), Kruse }(2015)^{+}\end{array}$ \\
\hline Goals & $\begin{array}{l}\text { Students' academic and professional goals coupled with hard work } \\
\text { and determination increased persistence in writing courses at a single } \\
\text { institution. } \\
\text { Villarreal }(2012)^{*}\end{array}$ & $\begin{array}{l}\text { Highest level of education student expects to complete correlates positively with } \\
\text { student outcomes. } \\
\text { Griffin (2010), Myers (2013) }{ }^{\dagger} \text {, Myers et al. (2015) } \\
\text { Students who enroll with the intention of transferring are more likely to transfer to a } \\
\text { 4-year institution. } \\
\text { LaSota and Zumeta (2016) }{ }^{\dagger} \text {, Myers et al. (2015) } \\
\text { Level of student commitment to institution or goal correlates positively with student } \\
\text { outcomes. } \\
\text { McCool (1984), Nora (1987), Nora et al. (1997), Solis (1995) }\end{array}$ \\
\hline Credits & & $\begin{array}{l}\text { Increases in credits attained or attempted within a specific time frame correlates } \\
\text { positively with student outcomes. } \\
\text { Doyle (2009), Gross et al. (2014), Laugerman and Shelley }(2013)^{+} \text {, Laugerman et al. } \\
(2015)^{\dagger} \text {, McCool (1984), Nutting (2011) } \\
\text { Increases in credits student transfers toward basic program correlate positively with } \\
\text { student outcomes. } \\
\text { Laugerman and Shelley }(2013)^{\dagger} \text {, Laugerman et al. }(2015)^{\dagger} \\
\text { Enrolling full-time correlates with an increase in likelihood student transfer. } \\
\text { LaSota and Zumeta }(2016)^{\dagger}\end{array}$ \\
\hline STEM & & $\begin{array}{l}\text { Successful completion of STEM courses correlates positively with student outcomes. } \\
\text { Chen and Soldner }(2013)^{\dagger}, \text { Kruse }(2015)^{\dagger} \text {, Myers et al. }(2015)^{\dagger} \text {, Wang }(2015)^{\dagger} \\
\text { Student's STEM aspirations correlate positively with their intent to persist. } \\
\text { Myers }(2013)^{\dagger} \\
\text { Majoring in STEM correlates positively with likelihood of student transfer relative to } \\
\text { students majoring in business and those who are "undeclared." } \\
\text { LaSota and Zumeta }(2016)^{\dagger}\end{array}$ \\
\hline
\end{tabular}

financial aid, child care services, and tutoring; help with both personal and college applications (e.g., financial aid, housing, and unemployment); advice regarding personal issues; and validation or encouragement. Advisors can provide students with invaluable resources and offer needed guidance. Students credited advisors for their persistence in their degree aspirations (Dorame, 2012; Jackson, 2013b; Sayasenh, 2012). Students reported that the support of advisors can remove a significant amount of pressure, enabling them to focus on their coursework (Dorame, 2012; Jackson, 2013b; Sayasenh, 2012).

Qualitative studies also described detailed accounts of negative advising experiences (Packard et al., 2012; Patterson, 2011; Ramirez, 2011; Wade, 2012). Students described being disappointed with advisors who read directly from course catalogs, could not answer their questions, referred students to multiple advisors, or gave students standardized and confusing guides to direct their course selection (Patterson, 2011; Wade, 2012). Packard et al. (2012) organized negative advisor actions into two categories: poor advising and passive advising. Poor advising includes advising students to retake courses they already passed, counseling them to take courses that would not transfer, and encouraging students to complete an associate degree before transfer even though the degree is not required. Passive advising practices included not informing students they could retake math placement tests to improve their scores, omitting important information about how similar courses would transfer differently, and failing to refer students to an appropriate resource when they were unable to answer the question. Low-quality advising left students to problem solve on their own. They self-advised by using the internet, relied on peer advising, or sought advising from department instructors or other staff, who may not be familiar with the intricacies of transfer credit policies (Patterson, 2011; Wade, 2012). In Wade's (2012) study of eight STEM majors, students who had negative advising experiences and could not access a network of information generally did not complete STEM degrees.

\section{Academic integration}

Several models of retention and/or persistence connect academic integration with student success (Pascarella \& Terenzini, 1980; Spady, 1970; Tinto, 1993). As noted in the "Introduction" section, many conceptualizations of academic integration that stem from Tinto's (1993) work can be conceptually and practically problematic, especially for non-traditional students (i.e., not full-time, 18-22year-old students living on campus) (Crisp et al., 2015; 
Lee et al., 2018). Academic integration considers the degree to which a student engages with the academic elements of the institution, including study groups, learning communities, social contact with instructors, meeting with academic advisors, and academic conversations with instructors. For these studies, academic integration meant student engagement in tutoring, study groups, or learning communities; engagement with instructors inside or outside of class; students' perception or frequency of interactions with instructors; or meeting with an academic advisor.

Academic integration was a factor in four quantitative studies and three qualitative studies. The quality score of the seven studies supporting influences of academic integration varied considerably, with one of the quantitative studies being low quality, two of the quantitative studies and two the qualitative studies being medium quality, and the remaining studies, one qualitative and one quantitative, being high quality. Based on this, academic integration has moderate support for influence on success of Latinx students, though the way it is operationalized that may not consider the personal circumstances and cultural contexts of Latinx students.

In qualitative studies, academic integration overlapped with other factors, such as peer interactions, instructorstudent interactions, and advising/counseling, revealing the intertwined nature of these factors. Qualitative studies identified resources and relationships that supported students' academic integration, including tutoring centers, student organizations, on-campus jobs, study groups, counseling, interaction with instructors, and learning communities (Patterson, 2011; Sayasenh, 2012; Wade, 2012). In all three studies, students mentioned tutors or study groups as a positive influence. Wade (2012) found that students who did not have a peer mentor often relied on study groups for integration into the STEM community. Patterson (2011) found women transfer students considered the lack of tutoring centers at their 4-year colleges to be a problem for multiple reasons. First, they had relied on such centers at their 2-year colleges not only for tutoring but also as a gathering place to find peer support. Second, they found networking with non-transfer students difficult. Patterson (2011) explained transfer students wanted to join study groups but found networking with non-transfer students difficult, since these students had already established peer networks, which were difficult for transfer students to enter.

One theme that was only articulated in Wade (2012) was that study participants felt like they needed to "earn their place" in the STEM community. All minority students "described experiences in which the lack of recognition, embodied by feeling excluded, the inability to find study partners, or the discomfort they experienced in class or in teacher's offices, impacted their STEM experience" (p. 69). Relationships with peer mentors helped students navigate these difficult social and/or academic experiences. Students who did not have a peer mentor integrated into the STEM community through student organizations, on-campus jobs, or study groups.

\section{Support services}

In addition to the 11 studies on advising/counseling, seven studies included a broader definition of support services. Qualitative studies mentioned tutoring centers, computer labs, and even student health services. Students who were unaware of these services or who had difficulties in accessing them had a higher likelihood of negative outcomes. Two quantitative studies included support services along with student perceptions of belonging to the institution and campus climate as factors correlated with positive student outcomes. However, all but one of the five qualitative studies were medium or low quality, and the two quantitative studies were of medium quality. As a result, we conclude the evidence for support services influencing student success as defined in this review is not compelling.

\section{Coursework articulation}

Seven studies, a moderate number in the context of this review, suggest coursework articulation and/or statewide transfer guides support the success of Latinx students. Of these, two were high-quality qualitative studies, four were medium quality, and one was a high-quality quantitative study. Five of the qualitative studies and the quantitative study focused on STEM-specific populations. In general, articulation agreements and transfer guides document which courses at 2-year institutions transfer to which courses at 4-year institutions. Sometimes they indicate whether credits that transfer to a 4-year institution also count toward completion of a degree program at a particular 4-year institution. We find the literature support for articulation agreements and transfer guides encouraging, but not compelling, because of the relatively small number of studies.

Although the overall evidence for articulation agreements and transfer guides is not compelling, the authors wanted to highlight institutional practices that could help students feel supported and successful at their 4year institutions after transfer. These practices were identified in one qualitative study (Jackson, 2013a). This study described how instructors and advisors from both 2-year and 4-year institutions worked together to suggest students retake particular courses when key concepts were missing from the previous course. STEM students credited consistent information from various institutional agents at both the 2-year and 4-year institutions with supporting their success in transferring because it relieved anxiety and facilitated transition to the university culture. Consistent messaging combined with 
smooth transfer of credits signaled to students that their institutions were communicating with each other and working as a team to support their success.

\section{Assets-based frameworks}

Three qualitative studies specifically focused on assets that Latinx 2-year college students bring to higher education, guided by the Yosso (2005) community cultural wealth framework of forms of capital that students of color draw upon to achieve academic success. The studies show how these forms of capital, on which an institution could choose to design its overall student support program, support success of Latinx students. All the qualitative studies were published after 2011, and there was one each of high, medium, and low quality. We did not find any quantitative studies as clearly focused on assets. Thus, we would describe the evidence for influence of forms of capital in the community cultural wealth framework on Latinx student success as underdeveloped. The authors think that more research is needed on this topic.

\section{Outreach}

Two qualitative studies (Dorame, 2012; Matos, 2015) addressed the effectiveness of outreach efforts to increase student knowledge of the opportunities higher education affords. They show that such efforts benefit transfer students if they (a) occur by middle school and (b) involve students' families and their communities. Given the small number of studies, evidence for effectiveness of outreach efforts is inconclusive. There is a substantial literature base focused specifically on outreach, which is beyond the scope of this review because it does not involve transfer students.

\section{Higher education instructors and other staff}

Table 4 summarizes factors extract from the 24 studies that examined influences of interactions with instructors and/or other staff at either 2- or 4-year institutions. These factors fell into two categories: (a) interactions with instructors and/or other staff, the broader category, and (b) teaching, a more restricted category of interactions. All 24 studies, the largest number supporting any factor in this review, suggested these factors support student success. There are 14 qualitative studies, all published after 2001 and all but three of high or medium quality; eight quantitative studies, six of which were published after 2010, and all but one of high or medium quality; and two mixed methods studies.

\section{Staff interactions with students}

Relationships with instructors were important to students and qualitative studies showed they positively or negatively influenced students' academic performance and degree aspirations. Fourteen qualitative studies indicated students benefitted from instructors who were invested in their learning, caring, engaging, and personable. Interactions that communicated these characteristics often occurred outside the classroom, as well as within. For example, a student working full-time remembered an instructor who went out of his way to offer tutoring sessions after noticing a dip in her grades (Ramirez, 2011). Students were motivated by instructors they perceived to be invested in their learning and cited this instructor support as a major contributor to their academic success (Barbosa and Seton Hall University, 2011; Sayasenh, 2012). From qualitative studies describing positive influences of instructor interactions, many students received individual attention while enrolled in 2-year institutions and perceived these instructors as more available and approachable than 4-year instructors (Coley \& Vallas, 2015; Jackson, 2013b; Patterson, 2011; Zhang \& Ozuna, 2015). Reasons may include smaller class sizes at 2-year institutions and demands on instructors at 4-year institutions beyond their teaching commitments (Coley \& Vallas, 2015; Zhang \& Ozuna, 2015).

Student appreciation for "caring" instructors appeared in several studies; however, ways in which students perceived instructors as caring varied (Arteaga, 2015; Barbosa and Seton Hall University, 2011; Dorame, 2012; Dowd et al., 2013). Some students described instructors who demonstrate they are invested in their students' learning and make extra efforts to support their success as caring. This extra effort included making themselves available to students or being sensitive to an individual student's needs or situation (Barbosa and Seton Hall University, 2011). Other instructors had high expectations for students, encouraged students' academic interests, and nurtured their confidence. Students reported high expectations coupled with support encouraged their degree aspirations (Dowd et al., 2013). Demonstrating caring does not always require significant effort. Students reported instructors were caring if they simply asked, "how are you?" and listened to the response (Patterson, 2011).

Students emphasized that instructors can help them build self-confidence and positively influence their ambition to earn a degree (Barbosa and Seton Hall University, 2011; Dorame, 2012; Dowd et al., 2013; Jackson, 2013b; Zhang \& Ozuna, 2015). While peer interactions and advising support students, instructors are exceptionally situated to help students overcome a sense of inadequacy (Dowd et al., 2013). As little as a single, encouraging conversation with an instructor can make students feel capable and affirmed that they could succeed in college (Dorame, 2012). Just having a helpful, knowledgeable instructor who is enthusiastic about his or her field can increase students' interest in a subject and motivate them 
to raise their degree aspirations (Dorame, 2012; Ramirez, 2011). When professors take the time to ask students about their degree aspirations and advise or encourage them, students perceive recognition of their potential (Dorame, 2012; Dowd et al., 2013). Validation and/or encouragement from an outside, authoritative source builds student confidence and positively influences students' degree aspirations (Dorame, 2012; Dowd et al., 2013; Jackson, 2013b; Zhang \& Ozuna, 2015). Studies also indicated that instructors explicitly advising students on the process of transfer can positively influence their degree trajectory (Dowd et al., 2013; Ramirez, 2011). Additionally, providing students access to education information/resources or insights into how to navigate through a specific field (e.g., engineering) can influence their motivation to persist or raise their degree aspirations (Dowd et al., 2013; Jackson, 2013b; Zhang \& Ozuna, 2015).

Unfortunately, instructor-student interactions have also been described as demotivating or uncomfortable experiences. For example, professors' actions can make students feel like they are wasting instructor time or that instructors do not feel students are smart enough to be in the class (Wade, 2012). Students also said they were intimidated by some instructors. A combination of expert knowledge and a "professional and serious" demeanor of some instructors made them seem less approachable (Prado, 2012, p. 97). This lack of approachability made students less likely to ask questions during lectures and more likely to seek out help from peers rather than these instructors.

Cejda and Hoover (2011) provide useful strategies from instructors to help avoid these negative interactions with students. They conducted roughly 40 instructor interviews at three 2-year colleges focused on serving Latinx students. These instructors noticed their students often relied on each other for help to avoid approaching the instructor. They concluded they needed to establish trust with students, so they would ask for assistance. Instructors also engaged with students outside class by initiating casual conversations or attending social or cultural events. This approach helped establish a sense of trust that often extended into the classroom. Instructors also acknowledged the importance of learning about Latinx culture and publicizing information about academic support programs, financial aid, and other programs (e.g., child care, transportation) to support student success.

\section{Teaching}

Influences of teaching were supported by significantly fewer studies than staff interactions; just five qualitative studies supported this factor. Three studies found that instructional strategies positively influenced student outcomes if they promoted peer interactions, for example, through group work, student-led instruction, and student-centered instruction. In one study, students credited instructors who clearly spent a lot of time preparing for class and creating materials with supporting them (Barbosa and Seton Hall University, 2011). Students also described needing an organized classroom where the instructor had a clear plan, shared class goals with their students, and worked to make sure students understood the material being presented (Barbosa and Seton Hall University, 2011). Instructors also described actions they took in class to help students form learning communities. These included instructors facilitating explicit class discussions emphasizing standards and expectations, expressing their willingness to work with students outside of class, and dedicating time in class for students to organize their study groups (Barbosa and Seton Hall University, 2011).

First-generation, English language learners reported having difficulty communicating with their instructors. Instructors confronted with this communication issue implemented several strategies, including using an interpreter, searching for texts in students' native language, and allowing them to speak or write in their native language (Barbosa and Seton Hall University, 2011Students who needed to learn English also noticed that professors in courses other than English seemed to be bound by a time-sensitive curriculum and did not always thoroughly explain concepts before moving on to the next (Barbosa and Seton Hall University, 2011).

Two qualitative studies, one in which students were interviewed (Barbosa and Seton Hall University, 2011) and one in which instructors were interviewed (Cejda \& Hoover, 2011), showed culturally responsive teaching and/or relevant curricula that echoed students' own experiences increased student interest in the course and positively influenced Latinx student engagement and outcomes. Participants in both studies noted that instructor practices focused on encouraging students positively impacted student experiences. For example, frequent feedback that is formative and constructive helped students prepare for summative assessments, and instructors also reported allowing students to revise and resubmit formative assessments multiple times (Barbosa and Seton Hall University, 2011; Cejda \& Hoover, 2011). Instructors tried to focus their feedback on suggesting areas for improvement rather than any shortcomings in student work.

Calling on students in class before they were comfortable could be demotivating for students (Barbosa and Seton Hall University, 2011; Cejda \& Hoover, 2011). To help students feel prepared to participate in class, instructors reviewed previous concepts before presenting new content and gave students time to reflect on or 
discuss concepts before asking for questions (Barbosa and Seton Hall University, 2011). In describing instructional practices that they found effective, instructors also remarked on the wide variation among Latinx students' experiences and preferences (Cejda \& Hoover, 2011).

\section{Students, their families, and their communities}

Table 5 presents 14 factors that are fundamentally different from the factors presented above. Tables 3 and 4 summarized factors over which institutions have some control, for example, advising and teaching. In contrast, Table 5 lists factors over which an institution has little or no direct control, or which might be at odds with their mission to serve specific communities.

Ten quantitative studies and one mixed methods study showed that one or more of these factors were, but should not be, predictive of student success: race/ethnicity, gender, age, starting at a 2-year institution, and citizenship status. This suggests the education system is not serving all students equally. We will not elaborate on these factors.

From a deficit-based perspective, the eight other factors in Table 5 can be interpreted as student deficits that must be addressed or ways in which students must be "fixed" to improve their success. These factors include the following:

- Preparation, the lack of which can be construed as a characteristic of students who do not belong in higher education

- Characteristics of the region or institution, which can be construed as characteristics of students coming from economically disadvantaged communities and institutions who do not belong in higher education

- English competency, the lack of which can be construed as a characteristic of students who do not belong in higher education

- First-generation and family support, which can be construed as characteristics of students without sufficient social capital to understand the relevance of higher education or the knowledge to navigate the pathways to success in higher education

- Finances, the lack of which can be construed as a characteristic of students without necessary financial resources to attend college

- Work/family obligations, which can be construed as a characteristic of students who must attend to needs other than focusing on work necessary to succeed in higher education; and

- Goals, which can be construed as a characteristic of students without sufficient aspirations and focus to succeed in higher education
Conversely, these factors can be interpreted as evidence that higher education institutions are currently not designed to serve these students who are entering the higher education system. From our assets-based perspective, we feel the factors that appear in Table 5 can result in student strengths that higher education structures sometimes fail to utilize. For example, the experience of balancing work, family obligations, and course work could help students' build skills around time management and organizing priorities, skills that would undoubtedly benefit them throughout their lives. However, the inflexibility of many structures within higher education makes it difficult for students whose circumstances require them to work. Therefore, we have chosen to focus our discussion on Tables 3 and 4 to develop conversations centered on actionable change and shifting institutional structures.

Finally, there are two factors in Table 5 that are different from many of the other factors in Table 5 as well as being different from the factors in Tables 3 and 4. So, in some ways they do not fit into any of the three tables. The first of these two factors is labeled "Credits." This factor summarizes findings that the more credits that a student has completed, the greater the likelihood of student success. The second factor is labeled "STEM." Since this is a study of factors influencing the success of Latinx transfer students in STEM fields, some elaboration may be justified. As shown in the table, the finding collects three results from quantitative studies. First, completing STEM courses correlates positively with student outcomes (Chen and Soldner, 2013; Kruse et al., 2015; Myers, 2015; Wang, 2015). This is consistent with the previous finding ("Credits") that the more courses a student completes and or transfers, the higher the likelihood that students will achieve positive outcomes. The second and third results are very specific results, each from a single quantitative study and the text in Table 5 is sufficient to explain the results.

\section{Discussion}

We reviewed the multiple factors that influenced success of Latinx students who matriculate at 2-year institutions. Although we found some quantitative studies focused on student characteristics traditionally framed as deficits, we identified 11 factors (Tables 3 and 4) that institutions, their instructors, and their other staff can influence to support Latinx students and build on the assets they bring to 2-year institutions and to 4-year institutions as transfer students. Specifically, the interactions that students have with peers, advisors and other academic staff, and their instructors are critical to their success. Students benefited from instructors and advisors who cared about them as individuals, engaged them, motivated them, helped them increase their self- 
confidence, helped them improve their emotional wellbeing, believed in them, supported them in dealing with difficult issues, and conveyed that they could be successful. The ability to form study groups (or join existing study groups in the case of transfer students) was an important mechanism for peer support. The importance of study groups identified in this study echoes findings from prior studies (Dennis et al., 2005; Llopart \& Esteban-Guitart, 2018; Ovink \& Veazey, 2011). These findings are consistent with prior reviews, especially those that critique Tinto's model. Given the importance of interaction with peers, instructors, and staff to the success of Latinx and transfer students, we found evidence that researchers need to develop more sophisticated conceptualizations of academic and social integration to guide future research and influence practice (e.g., Lee et al., 2018).

This review comes to many of the same conclusions of prior reviews (Crisp et al., 2015). In addition to overreliance on Tinto's conceptualization of academic and social integration, we identified many of the same categories of factors. Additionally, we contribute to the literature by showing that these same factors are indeed relevant to Latinx students enrolled at 2-year institutions, Latinx transfer students, and Latinx STEM majors, as well as critiquing the quality and theory in prior studies. We also show that Latinx STEM transfer students are still an understudied population. Further, we advance scholarship in this area by framing the results to highlight an assets-based perspective on supporting Latinx STEM transfer student success. We found evidence of greater emphasis on assets, including community cultural wealth theory in particular, in the qualitative studies.

Including qualitative, quantitative, and mixed methods studies in our systematic review enabled multiple benefits of triangulation (Greene et al., 1989). We were able to clarify which factors are supported by both quantitative and qualitative results, as well as a few gaps (Tables 3,4 and 5 ). We further validated many of the findings of individual studies. While the quantitative studies highlight the extent to which these factors influence student success, the qualitative studies illustrate how these factors operate. Several patterns emerged from the qualitative studies that illuminate the ways these interactions influenced student experiences. One very important gap identified here is in moving from a deficit to an assetsbased perspective, especially when quantitative methods are employed.

A large proportion of studies focused on student characteristics. A sizeable minority, 34\% (20 of 59) of all studies, including a slight majority, $52 \%$ (16 of 31), of quantitative studies appeared only in Table 5 (student, family, and community characteristics). This suggests quantitative studies tend to neglect factors related to institutional structures or faculty and staff. The Beginning Postsecondary Survey (BPS) used in several studies comprises detailed transcript, financial aid, institution type, and student and family characteristics data (National Center for Education Statistics, n.d.). While these longitudinal data are invaluable for tracking transfer students through multiple institutions, the nature of the items tends to reproduce a deficit approach to studying students from underrepresented backgrounds. Specifically, they do not include psychosocial measures and detailed questions about academic experiences or interactions (Crisp et al., 2015) that would further validate our main findings. The Science Study (Schultz, Woodcock, Estrada, Hernandez, Quartucci, Rodriguez, et al., n.d.) is a step in the right direction; this US national, longitudinal study of 1400 minority science students, asks questions about stereotype threat, ethnic identity (Irizarry \& Hunt, 2016), and mentorship (Estrada et al., 2018). Similarly, Hurtado's work was excluded from Crisp et al.'s (2015) prior review because it did not focus on "traditional" outcomes but instead on sense of belonging (Hurtado \& Carter, 1997), pluralistic thinking, and perception of racial climate (Hurtado \& Ponjuan, 2005). These items, which are so important to understanding underrepresented students' experiences in STEM higher education, have not been included in datasets that include majority students, such as BPS. Taking an assets-based approach to studying the experiences of underrepresented students will require broader datasets to integrate scales that have been shown to be particularly influential in Latinx and underrepresented students' experiences, such as belonging, perceptions of unwelcoming climates, and pluralistic thinking. If they were included, this might increase awareness, access, and statistical power in ways that would lead to research that would prompt effective interventions to broaden participation of Latinx and Black students in STEM. Additionally, more work is needed for data sets and analyses to link specific questions about interactions with peers, staff, and intervention programs with outcomes such as sense of belonging (e.g., Hurtado \& Carter, 1997; Hurtado \& Ponjuan, 2005) and to link sense of belonging and acculturative stress to more traditional outcomes such as GPA (e.g., Chun et al., 2016) or persistence to graduation.

As shown in Table 2, just two studies, both qualitative, focused on Latinx STEM transfer students. We had to synthesize findings from often separate studies of 2-year, transfer, Latinx and STEM students to understand the factors that support academic success of Latinx students that matriculate at 2-year institutions and transfer to 4year institutions to complete their STEM degrees. Studies that considered STEM majors as a variable or population are indicated in Tables 3, 4, and 5. Readers can see that these STEM studies are reasonably wellrepresented among the main categories of findings with 
a few notable exceptions. In Table 3, there are no STEM studies that explicitly referenced an assets-based framework in the analysis of their findings. Certainly, we can identify examples that use an assets-based perspective in studying STEM student success (e.g., Harper, 2010; Samuelson \& Litzler, 2016; Wilson-Lopez et al., 2016); however, we did not find evidence that this perspective is being applied to Latinx STEM transfer students specifically. In Table 3, there are also no STEM-specific studies on outreach related to higher education. Outreach may well be important in STEM recruitment, but research we found has not focused specifically on outreach to support Latinx STEM students in 2-year institutions. In Table 4, there are no pedagogy/teaching studies on STEM students; most of these were focused broadly on Latinx students' experiences with all instructors and were not conducted in a specific course. Our "Implications for Practice" section below expands on specific strategies that all instructors can follow to support Latinx students. Overall, however, we can conclude that many of the findings for non-STEM student populations are also relevant for STEM student populations. Additionally, there do not appear to be factors that are being investigated or found relevant only to STEM student populations.

\section{Implications for practice}

Table 4 summarizes our findings on how instructors influence the success of students that participated in the various studies, including Latinx students. Results in the table show positive instructor attitudes, approachability, accessibility, and encouragement contribute to constructive interactions with students while cultural disconnects between students and instructors can negatively affect student outcomes. Results in the table also show that instructional strategies that promote peer-to-peer interactions as well as culturally responsive teaching practices promote positive student outcomes. While constructive faculty-student interactions and instructional practices that support peer-to-peer interactions are well documented across multiple studies, our findings suggest that knowledge and understanding of culturally responsive teaching practices may be less widely known. Therefore, adopting a culturally relevant education framework, which we will present in this section, may act as a lever to improve both teaching practices as well as interactions between instructors and their students. We also examine how engaging in these assets-based pedagogies can shift instructors away from deficit mindsets and improve their interactions with students. Finally, we briefly discuss how institutions can support culturally relevant teaching practices as well as common misconceptions surrounding culturally relevant education.
Aronson and Laughter (2016) synthesized research from two seminal strands of literature, culturally relevant pedagogy (Ladson-Billings, 1995) and culturally responsive teaching (Gay, 2010), to create a framework for culturally relevant education (CRE). Although both bodies of research are founded in social justice principles and seek to create social change through classrooms, the two strands emphasize slightly different foci. While Ladson-Billings' work on culturally relevant pedagogy intends to influence instructors' attitudes and perspectives that translate into every aspect of their teaching, Gloria Gay's work on culturally responsive teaching focuses on teaching methods and practices instructors may use in their classrooms (Aronson \& Laughter, 2016). The integrated, inclusive CRE framework synthesizes a broader range of related works (Aronson \& Laughter, 2016; Dover, 2013).

Several reviews provide evidence that CRE practices benefit students in various ways. Aronson and Laughter (2016) have shown CRE practices have had direct, positive impact on student outcomes, specifically within STEM disciplines. They describe 13 studies that reported positive student outcomes in math and science courses implementing practices from the CRE framework. In another review of 45 classroom-based research studies, authors showed how explicit instructor actions, which could be related to CRE practices, benefitted students (Morrison et al., 2008). For example, Morrison et al. (2008) reported instructors using "student strengths as instructional starting points" and investing and taking "personal responsibility for students' success" (p. 436). Both sets of instructor actions provide examples of CRE practices. A third review offers students' perspectives of culturally relevant teaching. Byrd (2016) conducted a nationwide survey of 315 sixth through 12th grade students about their experiences with culturally relevant practices. Her findings showed CRE practices were significantly linked to both academic outcomes and racial identity development. In addition to supporting student outcomes, we propose that CRE practices promote positive interactions between instructors and their students by working against deficit-oriented perspectives.

The problem of deficit discourse framing diverse and low-income student populations in higher education is global. From the USA, to South Africa and Australia, researchers are working to problematize deficit thinking and move instructors and institutions away from viewing students and their families as the unit to be "fixed" (McKay \& Devlin, 2016; O'Shea et al., 2016; Smit, 2012). Many well-intentioned instructors are aware of different cultures, while simultaneously holding deficit-oriented mindsets. These deficit mindsets may lead to lower expectations of students, reify deficit stereo types, and 
undermine reform efforts (Nelson \& Guerra, 2014). Unfortunately, it can be difficult to shift deficit mindsets in individuals as these ideas are pervasive and often derived from larger beliefs about nondominant communities that permeate through society (García \& Guerra, 2004; Valencia, 2010). Achieving this radical shift seems to necessitate sustained, systematic efforts organized around specific frameworks.

Evidence suggests that professional development promoting use of CRE practices has the potential to shift participants' mindsets toward a more assets-based orientation and in turn, improve instructor-student interactions. For example, García and Guerra (2004) demonstrated that after completing development activities that created cognitive dissonance between ideas within culturally responsive pedagogy and previously held deficit beliefs, participants resolved those conflicts. Resolution prompted participants to examine and modify instructional practices in order to be more culturally responsive. Similarly, Warren (2018) argues for teaching perspective taking"adopting the social perspectives of others as an act and process of knowing" - to instructors to help them develop CRE practices. Perspective taking increases instructors' personal knowledge of students and the sociocultural context in which they are teaching. Acquiring personal knowledge of students and their communities can then work against assumptions on which deficit mindsets have been constructed. The knowledge gained from perspective taking supports instructors in how they respond to students within any given interaction. Instructors' critical awareness and expectations of students have been shown to be directly related to their behavior within classrooms that can impact students' ethnic and achievement identities (López, 2017). Thus, shifting instructors' mindsets and increasing their critical awareness through professional development designed around CRE practices is critical for improving instructor-student interactions.

While the CRE framework supports initiatives to improve instruction and interactions with students, implementation of such initiatives requires thorough understanding and thoughtful consideration. Hurried applications of these frameworks may create misconceptions that can lead to misuse. Twenty years after the initial development of culturally relevant pedagogy, Ladson-Billings (2014) reflected on the evolution of the theory and its misuses. She cautioned against a shallow interpretation of culturally relevant pedagogy, one that sometimes results in well-intentioned instructors integrating course materials reflective of their students' culture while ignoring critical aspects of the pedagogy. For example, instructors might choose a text that reflects common experiences of their students but fail to discuss or acknowledge policies that directly impact those students and their families (e.g., school choice, mass incarceration, school funding). To avoid such misinterpretations, we recommend that institutions both create teaching development programs on culturally relevant education and build infrastructure that supports their implementation. For example, the Center for Urban Education at the University of Southern California has developed self-assessment inventories to facilitate inquiry practices examining racial inequities within higher education. One of these self-assessment tools is based on the literature surrounding culturally relevant pedagogy; it guides instructors through a protocol to promote culturally inclusive practices (Dowd et al., 2012a, b).

Several studies have linked instructors' beliefs to their instructional decisions (Allendoerfer et al., 2014; Haan et al., 2017; Hora, 2014); therefore, it is reasonable to assert that instructors' beliefs influence their implementation of CRE practices. Since these personal beliefs often reflect school cultures, institutional adoption of CRE practices has the potential to support a systematic shift away from deficit discourses. For example, while institutions may disaggregate student outcome data by race or ethnicity (Dowd et al., 2012a), they cannot stop there. They should use an equity framework to examine student outcome data that could help shift instructors toward an assets-based perspective (Bensimon, 2005). Because culturally relevant pedagogy is deeply rooted in how instructors view students and their communities, systematic shifts to assets-based perspectives at the institutional level could support instructors in successfully implementing CRE practices. To support institutions in this effort, Khalifa et al. (2016) have synthesized the literature surrounding culturally responsive school leadership. They offer insight into how school leaders can engage in critical self-reflection while supporting the development of culturally responsive teaching, environments, and engagement with surrounding communities.

\section{Conclusion}

Our review has identified multiple factors that (a) have substantial support in literature with respect to the strength of their influence on success of Latinx students matriculating at 2-year institutions and transferring to 4year institutions and (b) institutions can apply to transform their practices and policies. That is, these are factors that are not characteristics of the students themselves, but factors that institutions can influence through actions that recognize the more diverse student population that higher education serves in the twenty-first century. These include (a) strengthening staff interactions with students; (b) promoting supportive peer interactions (e.g., study groups, living-learning communities, and peer mentors); (c) improving the cultural climate for all students; (d) improving quality of, access to, and student 
awareness of advising, counseling, and mentoring services; and (e) increasing availability and improving the quality of programs and services that support academic integration. Also, our systematic review has reinforced previous findings that significant student populations are disadvantaged with respect to academic success outcomes (see Table 5). For example, we know that first-generation students succeed at significantly lower rates than students where one or both parents graduated from college. Further studies are not needed to establish these facts. Instead, future studies on factors that influence success of Latinx students need to emphasize aspects that institutional policies, practices, and programs can apply. For example, supportive peer interactions promote student success. What aspects of these interactions (e.g., frequency, when they occur in the lives of students, characteristics of the peers) support success? To investigate these elements, initiatives that collect longitudinal data on broad segments of students in higher education (e.g., BPS) need to change items in their surveys. We conclude extensive structural changes are needed in the study of student success.

\section{Supplementary information}

Supplementary information accompanies this paper at https://doi.org/10. 1186/s40594-020-00215-6.

\section{Additional file 1 Appendix}

\section{Abbreviations}

STEM: Science, technology, engineering, and math; HSI: Hispanic-serving institution; BPS: Beginning Postsecondary Survey; CRE: Culturally relevant education

\section{Acknowledgements}

This research was supported by the US National Science Foundation's Division of Undergraduate Education through grant numbers 1446319 , 1446323, 1446369, and 1829094 and the Division of Graduate Education through grant number 1610403. The opinions expressed are those of the authors and not necessarily those of the National Science Foundation.

\section{Authors' contributions}

Foster searched several databases with agreed-upon search terms to retrieve relevant studies and organized these records. Borrego, Foster, Froyd, and Martin worked together to develop inclusion criteria and screen identified articles using Qualtrics web-based survey software. Froyd and Winterer coded included quantitative studies and organized the significant factors from each study. They used this information to assess the quality of each quantitative study. Winterer coded the qualifying mixed methods and qualitative studies. Martin assessed the quality of the qualitative studies while Borrego assessed the quality of the mixed methods studies. Winterer used the coding data to create Table 3, Table 4, and Table 5. All authors contributed to the writing of this manuscript. All authors read and approved the final manuscript.

\section{Funding}

This research was supported by grants from the National Science Foundation (DUE-1446319; DUE-1446323; DUE-1446369; DUE-1829094; DGE-1610403). Any opinions, findings, and conclusions or recommendations expressed in this material are those of the author(s) and do not necessarily reflect the views of the National Science Foundation.

\section{Availability of data and materials}

The example data for this study is the set of articles that are available to all researchers. The references show the articles that were identified through this study cited in the text. See Appendix for a complete list of included studies.

\section{Competing interests}

The authors declare that they have no competing interests.

\section{Author details}

${ }^{1}$ Department of Curriculum and Instruction, University of Texas at Austin, Austin, USA. ²Department of Engineering Education, The Ohio State University, Columbus, USA. ${ }^{3}$ Department of Mechanical Engineering, University of Texas at Austin, Austin, USA. ${ }^{4}$ Medical Sciences Library, University Libraries, Texas A\&M University, MS \#4462, College Station, TX 77843, USA.

Received: 23 September 2019 Accepted: 2 April 2020

Published online: 06 July 2020

\section{References}

*denotes that the study was included in the systematic review, see full list of included studies in appendix

*Alexander, B. C., Garcia, V., Gonzalez, L., Grimes, G., \& O'Brien, D. (2007). Barriers in the transfer process for Hispanic and Hispanic immigrant students. Journal of Hispanic Higher Education, 6(2), 174-184. https://doi.org/10.1177/ 1538192706297440

*Allen, T. O., \& Zhang, Y. (2016). Dedicated to their degrees: Adult transfer students in engineering. Community College Review, 44(1), 70-86. https://doi. org/10.1177/0091552115617018

Allendoerfer, C., Wilson, D., Kim, M. J., \& Burpee, E. (2014). Mapping beliefs about teaching to patterns of instruction within science, technology, engineering, and mathematics. Teaching in Higher Education, 19(7), 758-771 https://doi. org/10.1080/13562517.2014.901962.

*Anderson, M. F., Perez, L. C., Jones, D., \& Zafft, C. (2011). Success factors for students transferring into undergraduate engineering degree programs. Paper presented at the 41st Annual Frontiers in Education Conference: Celebrating 41 Years of Monumental Innovations from Around the World, FIE 2011, Rapid City, SD.

Aronson, B., \& Laughter, J. (2016). The theory and practice of culturally relevant education: A synthesis of research across content areas. Review of Educational Research, 86(1), 163-206 https://doi.org/10.3102/0034654315582066.

*Arteaga, B. E. (2015). Applying cultura in the community college counseling practice. Community College Journal of Research and Practice, 39(8), 708726. https://doi.org/10.1080/10668926.2013.876374

Barbosa, L. L., \& Seton Hall University. (2011). A study of college access and academic success among first generation Hispanic language minority students at the community college level. (Doctoral dissertation). Available from ProQuest. (3520136)

Bauman, K. (2017). School enrollment of the Hispanic population: Two decades of growth. [U. S. Census Bureau Blog post]. Retrieved from https://www. census.gov/newsroom/blogs/random-samplings/2017/08/school_ enrollmentof.html

Bensimon, E. M. (2005). Closing the achievement gap in higher education: An organizational learning perspective. New Directions for Higher Education, 2005(131), 99-111 https://doi.org/10.1002/he.190.

Borrego, M., Foster, M. J., \& Froyd, J. E. (2014). Systematic literature reviews in engineering education and other developing interdisciplinary fields. Journal of Engineering Education, 103(1), 45-76 https://doi.org/10.1002/jee.20038.

Brown, J., \& Kurzweil, M. (2017). Instructional quality, student outcomes, and institutional finances. Washington, DC: American Council on Education Retrieved from https://www.acenet.edu/Documents/Instructional-QualityStudent-Outcomes-and-Institutional-Finances.pdf.

*Budd, D., \& Stowers, G. N. L. (2015). Group differences in California community college transfers. Community College Journal of Research and Practice, 39(9), 865-879. https://doi.org/10.1080/10668926.2013.875496

Byrd, C. M. (2016). Does culturally relevant teaching work? An examination from student perspectives. SAGE Open, 6(3) https://doi.org/10.1177/ 2158244016660744

Camacho, M. M., \& Lord, S. M. (2013). The borderlands of education: Latinas in engineering. Latham: Lexington Books. 
*Castillo, C. (2011). Community college transfer student involvement experiences at a selective, private four-year university. (Doctoral dissertation). Available from ProQuest. (916591117)

*Cejda, B. D., \& Hoover, R. E. (2011). Strategies for faculty-student engagement: How community college faculty engage Latino students. Journal of College Student Retention: Research, Theory \& Practice, 12(2), 135-153. https://doi. org/10.2190/CS.12.2.b

${ }^{*}$ Chen, X., \& Soldner, M. (2013). STEM attrition: College students' paths into and out of STEM fields. Statistical analysis report. National Center for Education Statistics, NCES 2014-001. Retrieved from https://nces.ed.gov/pubs2014/2014 001rev.pdf

Chun, H., Marin, M. R., Schwartz, J. P., Pham, A., \& Castro-Olivo, S. M. (2016). Psychosociocultural structural model of college success among Latina/o students in Hispanic-serving institutions. Journal of Diversity in Higher Education, 9(4), 385 https://doi.org/10.1037/a0039881.

Coalition for Evidence-Based Policy. (2007). Hierarchy of study designs for evaluation the effectiveness of a STEM education project or practice. Retrieved from http://coalition4evidence.org/wp-content/uploads/2009/05/ study-design-hierarchy-6-4-09.pdf

Cohn, D. (2010). Census History: Counting Hispanics. Retrieved from http://www pewsocialtrends.org/2010/03/03/census-history-counting-hispanics-2/

${ }^{*}$ Coley, B. C., \& Vallas, C. A. (2015). Tapping into the talent: Exploring the barriers of the engineering transfer pathway. Paper presented at the 2015 122nd ASEE Annual Conference and Exposition, Seattle, WA.

Creswell, J. W., \& Plano Clark, V. L. (2007). Designing and conducting mixed methods research. Thousand Oaks, CA: Sage.

*Crisp, G., \& Delgado, C. (2014). The impact of developmental education on community college persistence and vertical transfer. Community College Review, 42(2), 99-117. https://doi.org/10.1177/0091552113516488

Crisp, G., Taggart, A., \& Nora, A. (2015). Undergraduate Latina/o students: A systematic review of research identifying factors contributing to academic success outcomes. Review of Educational Research, 85(2), 249-274 https://doi. org/10.3102/0034654314551064

*Del Rio, R. (2013). Student engagement as a predictor of intent to persist among Latino students at community colleges in Texas. (Doctoral dissertation). Available from ProQuest. (3579197)

Demetriou, C., \& Schmitz-Sciborski, A. (2011). Integration, motivation, strengths and optimism: Retention theories past, present, and future.

Dennis, J. M., Phinney, J. S., \& Chuateco, L. I. (2005). The role of motivation, parental support, and peer support in the academic success of ethnic minority first-generation college students. Journal of College Student Development, 46(3), 223-236 https://doi.org/10.1353/csd.2005.0023.

*Dorame, F. (2012). Latino males degree aspirations in community college: A qualitative study. (Doctoral dissertation). Available from ProQuest. (3544951)

Dover, A. G. (2013). Teaching for social justice: From conceptual frameworks to classroom practices. Multicultural Perspectives, 15(1), 3-11 https://doi.org/10. 1080/15210960.2013.754285

Dowd, A. C., Malcom, L., Nakamoto, J., \& Bensimon, E. M. (2012a). Institutional researchers as teachers and equity advocates: Facilitating organization learning and change. In E. M. Bensimon \& L. Malcom (Eds.), Confronting equity issues on campus: Implementing the equity scorecard in theory and practice (pp. 191-215). Herndon: Stylus Publishing

*Dowd, A. C., Pak, J. H., \& Bensimon, E. M. (2013). The role of institutional agents in promoting transfer access. Education Policy Analysis Archives, 21(15), 1-43. https://doi.org/10.14507/epaa.v21n15.2013

Dowd, A. C., Sawatzky, M., Rall, R. M., \& Bensimon, E. M. (2012b). Action research: An essential practice for twenty-first century assessment. In R. T. Palmer, D. C. Maramba, \& M. Gasman (Eds.), Fostering success of ethnic and racial minorities in STEM: The role of Minority Serving Institutions (pp. 149-167). New York: Routledge.

*Doyle, W. R. (2009). Impact of increased academic intensity on transfer rates: An application of matching estimators to student-unit record data. Research in Higher Education, 50(1), 52-72. https://doi.org/10.1007/s11162-008-9107-6

*Elrod, M. R. (2002). A comparison of institutional factors and student satisfaction: Retention implications in a Hispanic-serving community college. (Doctoral dissertation). Available from ProQuest. (3053640)

Estrada, M., Hernandez, P. R., \& Schultz, P. W. (2018). A longitudinal study of how quality mentorship and research experience integrate underrepresented minorities into STEM careers. CBE-Life Sciences Education, 17(1), 9 https://doi. org/10.1187/cbe.17-04-0066.
European Centre for the Development of Vocational Training. (2008). Modernising vocational education and training: Fourth report on vocational training research in Europe: background report. Luxembourg: Office for Official Publications of the European Communities.

Ferguson, D. L. (2008). International trends in inclusive education: The continuing challenge to teach each one and everyone. European Journal of special needs education, 23(2), 109-120.

Florian, L. (2012). Preparing teachers to work in inclusive classrooms: Key lessons for the professional development of teacher educators from Scotland's inclusive practice project. Journal of Teacher Education, 63(4), 275-285.

Fry, R., \& Lopez, M. H. (2012). Hispanic student enrollments reach new highs in 2011. In Pew Research Center Retrieved from http://www.pewhispanic.org/2 012/08/20/hispanic-student-enrollments-reach-new-highs-in-2011.

Gándara, P., Alvarado, E., Driscoll, A., \& Orfield, G. (2012). Building pathways to transfer: Community colleges that break the chain of failure for students of color. In Civil Rights Project/Proyecto Derechos Civiles Retrieved from: https:// www.civilrightsproject.ucla.edu/research/college-access/diversity/buildingpathways-to-transfer-community-colleges-that-break-the-chain-of-failure-forstudents-of-color.

García, S. B., \& Guerra, P. L. (2004). Deconstructing deficit thinking: Working with educators to create more equitable learning environments. Education and Urban Society, 36(2), 150-168 https://doi.org/10.1177/0013124503261322.

Gay, G. (2010). Culturally responsive teaching: Theory, research and practice (2nd ed. ). New York: Teachers College Press.

Gough, D., Oliver, S., \& Thomas, J. (2012). An introduction to systematic reviews. Los Angeles: Sage.

Greene, J. C., Caracelli, V. J., \& Graham, W. F. (1989). Toward a conceptual framework for mixed-method evaluation designs. Educational Evaluation and Policy Analysis, 11(3), 255-274.

*Griffin, C. M. (2010). Retention and graduation of Hispanics in American community colleges. (Doctoral dissertation). Available from ProQuest. (3413932)

*Gross, J. P. K., Zerquera, D., Inge, B., \& Berry, M. (2014). Latino associate degree completion: Effects of financial aid over time. Journal of Hispanic Higher Education, 13(3), 177-190. https://doi.org/10.1177/1538192714531293

Guba, E. G., \& Lincoln, Y. S. (1989). Fourth generation evaluation. Newbury Park: Sage Publications.

Haan, J. E., Gallagher, C. E., \& Varandani, L. (2017). Working with linguistically diverse classes across the disciplines: Faculty beliefs. Journal of the Scholarship of Teaching and Learning, 17(1), 37-51 https://doi.org/10.14434/ v17i1.20008.

Harper, S. R. (2010). An anti-deficit achievement framework for research on students of color in STEM. New Directions for Institutional Research, 2010(148), 63-74.

Holloway, B. M., Reed, T., Imbrie, P. K., \& Reid, K. (2014). Research-informed policy change: A retrospective on engineering admissions. Journal of Engineering Education, 103(2), 274-301 https://doi.org/10.1002/jee.20046.

*Hooshangi, S., Willford, J., \& Behrend, T. (2015). Self-regulated learning in transfer students: A case study of non-traditional students. Paper presented at the 2015 IEEE Frontiers in Education Conference, FIE 2015, El Paso, TX.

Hora, M. T. (2014). Exploring faculty beliefs about student learning and their role in instructional decision-making. The Review of Higher Education, 38(1), 37-70 https://doi.org/10.1353/rhe.2014.0047.

Hurtado, S., \& Carter, D. F. (1997). Effects of college transition and perceptions of the campus racial climate on Latino college students' sense of belonging. Sociology of Education, 70(4), 324-345 https://doi.org/10.2307/2673270.

Hurtado, S., \& Ponjuan, L. (2005). Latino educational outcomes and the campus climate. Journal of Hispanic Higher Education, 4(3), 235-251 https://doi.org/10. $1177 / 1538192705276548$.

Irizarry, Y., \& Hunt, M. O. (2016). The dynamics of ethnic identity and personal well-being: A multi-group comparison. In J. E. Stet \& R. T. Serpe (Eds.), New Directions in Identity Theory and Research (pp. 395-416). New York: Oxford University Press.

* Jackson, D. (2013a). A balancing act: Impacting and initiating the success of African American female community college transfer students in STEM into the HBCU environment. Journal of Negro Education, 82(3), 255-271. https:// doi.org/10.7709/jnegroeducation.82.3.0255

* Jackson, D. (2013b). Making the connection: The impact of support systems on female transfer students in science, technology, engineering, and mathematics (STEM). Community College Enterprise, 19(1): 19-33. 
Khalifa, M. A., Gooden, M. A., \& Davis, J. E. (2016). Culturally responsive school leadership: A synthesis of the literature. Review of Educational Research, 86(4), 1272-1311 https://doi.org/10.3102/0034654316630383.

*Klement, E. C., \& Bower, B. L. (2012). Transfer rates of Texas Hispanic community college students to 4-year institutions: Selected institutional factors. (Doctora dissertation). Available from ProQuest. (3538109)

*Knight, D. B., Bergom, I. M., Burt, B. A., \& Lattuca, L. R. (2014). Multiple starting lines: Pre-college characteristics of community college and four-year institution engineering students. Paper presented at the 121st ASEE Annual Conference and Exposition: 360 Degrees of Engineering Education, Indianapolis, IN

Knobloch, K., Yoon, U., \& Vogt, P. M. (2011). Preferred reporting items for systematic reviews and meta-analyses (PRISMA) statement and publication bias. Journal of Cranio-Maxillofacial Surgery, 39(2), 91-92 https://doi.org/10. 1371/journal.pmed.1000097.

*Kruse, T., Starobin, S. S., Chen, Y., Baul, T., \& Santos Laanan, F. (2015). Impacts of intersection between social capital and finances on community college students' pursuit of STEM degrees. Community College Journal of Research and Practice, 39(4), 324-343. https://doi.org/10.1080/10668926.2014.981893

*Laanan, F. S., Jackson, D. L., \& Rover, D. T. (2011). Engineering transfer students: Characteristics, experiences, and student outcomes. Paper presented at the 118th ASEE Annual Conference and Exposition, Vancouver, BC, Canada.

Ladson-Billings, G. (1995). But that's just good teaching! The case for culturally relevant pedagogy. Theory Into Practice, 34(3), 159-165 https://doi.org/10. 1080/00405849509543675.

Ladson-Billings, G. (2014). Culturally relevant pedagogy 2.0: a.k.a. the remix. Harvard Educational Review, 84(1), 74-84 https://doi.org/10.17763/haer.84.1. p2rj131485484751.

*LaSota, R., \& Zumeta, W. (2016). What matters in increasing community college students' upward transfer to the baccalaureate degree: Findings from the Beginning Postsecondary Study 2003-2009. Research in Higher Education, 57(2), 152-189.

*Laugerman, M., Rover, D., Shelley, M., \& Mickelson, S. (2015). Determining graduation rates in engineering for community college transfer students using data mining. International Journal of Engineering Education, 31(6), 1448-1457.

*Laugerman, M. R., \& Shelley, M. (2013). A structural equation model correlating success in engineering with academic variables for community college transfer students. Paper presented at the 120th ASEE Annual Conference and Exposition, Atlanta, GA

*Lee, D. (2014). The transition of Latina immigrant community college from ESL to transfer readiness. (Doctoral dissertation). Available from ProQuest (3580201)

Lee, W., Godwin, A., \& Nave, A. L. H. (2018). Development of the engineering student integration instrument: Rethinking measures of integration. Journal of Engineering Education, 107(1), 30-55 https://doi.org/10.1002/jee.20184.

*Libarios, E. N. D., Jr. (2013). Social stratification and higher education outcomes: The case of Filipinos in Hawai i. (Doctoral dissertation). Available from ProQuest. (3577236)

Llopart, M., \& Esteban-Guitart, M. (2018). Funds of knowledge in 21st century societies: inclusive educational practices for under-represented students. A literature review. Journal of Curriculum Studies, 50(2), 145-117 https://doi.org/ 10.1080/00220272.2016.1247913.

López, F. A. (2017). Altering the trajectory of the self-fulfilling prophecy: Assetbased pedagogy and classroom dynamics. Journal of Teacher Education, 68(2), 193-212 https://doi.org/10.1177/0022487116685751.

*Marra, R. M., Tsai, C.-L., Bogue, B., \& Pytel, J. L. (2015). Alternative pathways to engineering success--Using academic and social integration to understand two-year engineering student success. American Journal of Engineering Education, 6(2), 69-83.

Martin, J. P., Choe, N. H., Halter, J., et al. (2017). Interventions supporting baccalaureate achievement of Latinx STEM students matriculating at 2-year institutions: A systematic review. Journal of Research in Science Teaching, 56(4), 440-464 https://doi.org/10.1002/tea.21485.

* Martin, J. P., Simmons, D. R., \& Yu, S. L. (2013). The role of social capital in the experiences of Hispanic women engineering majors. Journal of Engineering Education, 102(2), 227-243. https://doi.org/10.1002/jee.20010

*Massi, L., Lancey, P., Nair, U., Straney, R., Georgiopoulos, M., \& Young, C. (2012, October). Engineering and computer science community college transfers and native freshmen students: Relationships among participation in extracurricular and co-curricular activities, connecting to the university campus, and academic success. Paper presented at the 42nd Annual Frontiers in Education Conference, FIE 2012, Seattle, WA.

*Matos, J. M. D. (2015). "La Familia": The important ingredient for Latina/o college student engagement and persistence. Equity \& Excellence in Education, 48(3), 436-453. https://doi.org/10.1080/10665684.2015.1056761

* McCool, A. C. (1984). Factors influencing Hispanic student retention within the community college. Community/Junior College Quarterly of Research and Practice, 8(1-4), 19-37. https://doi.org/10.1080/0361697840080103

McKay, J., \& Devlin, M. (2016). Low income doesn't mean stupid and destined for failure: Challenging the deficit discourse around students from low SES backgrounds in higher education. International Journal of Inclusive Education, 20(4), 347-363 https://doi.org/10.1080/13603116.2015.1079273.

Meier, K. J., \& Stewart, J. (1991). The politics of Hispanic education: Un paso pa'lante y dos pa'tras. Albany: SUNY Press.

*Mooring, R. D., \& Mooring, S. R. (2016). Predictors of timely baccalaureate attainment for underrepresented minority community college transfer students. Community College Journal of Research \& Practice, 40(8), 681-694. https://doi.org/10.1080/10668926.2015.1070775

Morrison, K. A., Robbins, H. H., \& Rose, D. G. (2008). Operationalizing culturally relevant pedagogy: A synthesis of classroom-based research. Equity \& Excellence in Education, 41(4), 433-452 https://doi.org/10.1080/ 10665680802400006.

*Museus, S. D., Jayakumar, U. M., \& Robinson, T. (2012). Modeling racial differences in the effects of racial representation on 2-year college student success. Journal of College Student Retention: Research, Theory \& Practice, 13(4), 549-572. https://doi.org/10.2190/CS.13.4.g

*Myers, B., Starobin, S. S., Chen, Y., Baul, T., \& Kollasch, A. (2015). Predicting community college student's intention to transfer and major in STEM: Does student engagement matter? Community College Journal of Research and Practice, 39(4), 344-354. https://doi.org/10.1080/10668926.2014.981896

*Myers, B. M. (2013). A study of the influence of student engagement on community college students' intentions to transfer and STEM aspirations. (Doctoral dissertation). Available from ProQuest. (3566116)

National Academies. (2016). In S. Malcom \& M. Feder (Eds.), Barriers and opportunities for 2-year and 4-year STEM degrees: Systemic change to support diverse student pathways. Washington, DC: National Academies Press. https:// doi.org/10.17226/21739.

National Center for Education Statistics. (n.d.). PowerStats. Retrieved from https:// nces.ed.gov/datalab/index.aspx

National Science Foundation. (2015). Women, minorities, and persons with disabilities in science and engineering: 2015 (Special Report NSF 15-311). Retrieved http://www.nsf.gov/statistics/wmpd/

Nelson, S. W., \& Guerra, P. L. (2014). Educator beliefs and cultural knowledge: Implications for school improvement efforts. Educational Administration Quarterly, 50(1), 67-95 https://doi.org/10.1177/0013161X13488595.

*Nora, A. (1987). Determinants of retention among Chicano college students: A structural model. Research in Higher Education, 26(1), 31-59. https://doi.org/ 10.1007/BF00991932

Nora, A., \& Crisp, G. (2009). Hispanics and higher education: An overview of research, theory, and practice. In J. C. Smart (Ed.), Higher education: Handbook of theory and research (Vol. 24, pp. 321-358). New York: Springer.

*Nora, A., Kraemer, B., \& Itzen, R. (1997). Persistence among non-traditional Hispanic college students: A causal model. Paper presented at the Annual Meeting of the Association for the Study of Higher Education, Albuquerque, NM.

*Nutting, A. W. (2011). Community college transfer students' probabilities of baccalaureate receipt as a function of their prevalence in four-year colleges and departments. Education Economics, 19(1), 65-87. https://doi.org/10.1080/ 09645290802500560

O'Shea, S., Lysaght, P., Roberts, J., \& Harwood, V. (2016). Shifting the blame in higher education - social inclusion and deficit discourses. Higher Education Research \& Development, 35(2), 322-336 https://doi.org/10.1080/07294360. 2015.1087388.

OECD. (2015). How is the global talent pool changing (2013, 2030)? Paris: Education Indicators in Focus, No. 31, OECD Publishing https://doi.org/10. 1787/5js331f9jk41-en.

Oseguera, L., Locks, A. M., \& Vega, I. I. (2009). Increasing Latina/o students' baccalaureate attainment: A focus on retention. Journal of Hispanic Higher Education, 8(1), 23-53 https://doi.org/10.1177/1538192708326997.

Ovink, S. M., \& Veazey, B. D. (2011). More than "getting us through:" A case study in cultural capital enrichment of underrepresented minority undergraduates. 
Research in Higher Education, 52(4), 370-394 https://doi.org/10.1007/s11162010-9198-8

*Packard, B. W. L., Gagnon, J. L., \& Senas, A. J. (2012). Navigating community college transfer in science, technical, engineering, and mathematics fields. Community College Journal of Research and Practice, 36(9), 670-683. https:// doi.org/10.1080/10668926.2010.495570

Padilla, R. (2007). Camino de la Universidad: The road to college. In Lumina Foundation for Education Retrieved from https://www.luminafoundation.org/ files/publications/The_Road_To_College_for_Latinos.pdf.

Pascarella, E. T., \& Terenzini, P. T. (1980). Predicting freshman persistence and voluntary dropout decisions from a theoretical model. The Journal of Higher Education, 51(1), 60-75 https://doi.org/10.1080/00221546.1980.11780030.

*Patterson, S. J. (2011). Women engineering transfer students: The community college experience. Corvallis: Oregon State University.

Petticrew, M., \& Roberts, H. (2006). Systematic reviews in the social sciences: A practical guide. Malden: Blackwell Publishing.

*Prado, R. E. (2012). Peers as institutional agents: Acquiring social capital through peer interactions. (Doctoral dissertation). Available from ProQuest. (3514290)

* Ramirez, R. A. (2011). Chicanas/os and Latinas/os crossing institutional fronteras: Critical race counterstories along the college transfer pipeline at a Sacramento Valley community college. Davis: University of California.

*Rodriguez, O. (2013). Examining the effects of academic English as a second language pathways at the community college: A mixed methods study. (Doctoral dissertation). Available from ProQuest. (3561856)

Samuelson, C. C.. \& Litzler, E. (2016). Community cultural wealth: An assets-based approach to persistence of engineering students of color. Journal of Engineering Education, 105(1), 93-117 https://doi.org/10.1002/jee.20110

*Sanchez, M. M. (2012). Aspirations, barriers, and transfer opportunities for Latina and Latino community college students. (Doctoral dissertation). Available from ProQuest. (3513226)

* Sayasenh, S. (2012). A comparative study of border crossers and borderland students of Mexican heritage: Their educational experiences and mediating factors. (Doctoral dissertation). Available from ProQuest. (3513840)

Schultz, W., Woodcock, A., Estrada, M., Hernandez, P., Quartucci, S., Rodriguez, R., ... Lopez, L. (n.d.). The Science Study. National Institutes of Health. Retrieved from http://thesciencestudy.csusm.edu

Smit, R. (2012). Towards a clearer understanding of student disadvantage in higher education: Problematizing deficit thinking. Higher Education Research \& Development, 31(3), 369-380 https://doi.org/10.1080/07294360.2011.634383.

*Solis, E., Jr. (1995). Regression and path analysis models of Hispanic community college students' intent to persist. Community College Review, 23(3), 3-15. https://doi.org/10.1177/009155219502300302

Spady, W. G. (1970). Dropouts from higher education: An interdisciplinary review and synthesis. Interchange, 1(1), 64-85 https://doi.org/10.1007/bf02214313.

Tinto, V. (1993). Leaving college: Rethinking the causes and cures of student attrition (2nd ed.). Chicago: University of Chicago Press.

Towne, L., \& Shavelson, R. J. (2002). Scientific research in education. Washington, D. C.: National Academy Press.

*Turner, C. S. V. (1990). It takes two to transfer: Relational networks and educational outcomes. Community College Review, 19(4), 27-33. https://doi. org/10.1177/009155219201900405

Turner, T. L., Balmer, D. F., \& Coverdale, J. H. (2013). Methodologies and study designs relevant to medical education research. International Review of Psychiatry, 25, 301-310 https://doi.org/10.3109/09540261.2013.790310.

Valencia, R. R. (2010). Dismantling contemporary deficit thinking: Educational thought and practice. New York: Routledge https://doi.org/10.4324/ 9780203853214.

*Villarreal, M.d. L d. L. (2012). African American and Latino/a community college student persisters in developmental and college-level writing courses. (Doctoral dissertation). Available from ProQuest. (3519857)

*Wade, R. H. (2012). Feeling different: An examination of underrepresented minority community college students' major persistence intentions through the lens of STEM identity. (Doctoral dissertation). Available from ProQuest. (3521647)

Walton, G. M., \& Spencer, S. J. (2009). Latent ability: Grades and test scores systematically underestimate the intellectual ability of negatively stereotyped students. Psychological Science, 20(9), 1132-1139 https://doi.org/10.1111/j. 1467-9280.2009.02417.x

*Wang, X. (2015). Pathway to a baccalaureate in STEM fields: Community colleges a viable route and does early STEM momentum matter? Educational
Evaluation and Policy Analysis, 37(3), 376-393. https://doi.org/10.3102/ 0162373714552561

Warren, C. A. (2018). Empathy, teacher dispositions, and preparation for culturally responsive pedagogy. Journal of Teacher Education, 69(2), 169-183 https:// doi.org/10.1177/0022487117712487.

*Wassmer, R., Moore, C., \& Shulock, N. (2004). Effect of racial/ethnic composition on transfer rates in community colleges: Implications for policy and practice. Research in Higher Education, 45(6), 651-672. https://doi.org/10.1023/B:RIHE. 0000040267.68949.d1

*Wilson, J. C. (2012). Persistence of Latino students in community colleges: An empowerment model addressing acculturative stress. (Doctoral dissertation). Available from ProQuest. (3513383)

Wilson-Lopez, A., Mejia, J. A., Hasbún, I. M., \& Kasun, G. S. (2016). Latina/o adolescents' funds of knowledge related to engineering. Journal of Engineering Education, 105(2), 278-311 https://doi.org/10.1002/jee.20117.

*Wood, J. L., Nevarez, C., \& Hilton, A. A. (2012). Determinants of transfer among community college students. Journal of Applied Research in the Community College, 19(2), 63-68.

Yosso, T. J. (2005). Whose culture has capital? A critical race theory discussion of community cultural wealth. Race, Ethnicity and Education, 8(1), 69-91 https:// doi.org/10.1080/1361332052000341006.

*Zhang, Y., \& Ozuna, T. (2015). Pathways to engineering: The validation experiences of transfer students. Community College Journal of Research and Practice, 39(4), 355-365. https://doi.org/10.1080/10668926.2014.981892

\section{Publisher's Note}

Springer Nature remains neutral with regard to jurisdictional claims in published maps and institutional affiliations.

\section{Submit your manuscript to a SpringerOpen ${ }^{\circ}$ journal and benefit from:}

- Convenient online submission

- Rigorous peer review

Open access: articles freely available online

- High visibility within the field

- Retaining the copyright to your article

Submit your next manuscript at $\boldsymbol{\nabla}$ springeropen.com 